\title{
Comparing climate sensitivity, past and present
}

Eelco J. Rohling1,a,b, ${ }^{*}$, Gianluca Marino ${ }^{1, a}$, Gavin L. Foster ${ }^{b}$, Philip A. Goodwin ${ }^{\mathrm{b}}$, Anna S. von der Heydtc, and Peter Köhler ${ }^{\mathrm{d}}$

a. Research School of Earth Sciences, The Australian National University, Canberra, ACT 2601, Australia. (eelco.rohling@anu.edu.au; gianluca.marino@anu.edu.au)

b. Ocean and Earth Science, University of Southampton, National Oceanography Centre, Southampton S014 3ZH, UK. (gavin.foster@noc.soton.ac.uk; p.a.goodwin@soton.ac.uk)

c. Institute for Marine and Atmospheric Research, Utrecht and Center for Extreme Matter and Emergent Phenomena, Utrecht University, Princetonplein 5, 3584 CC Utrecht, the Netherlands. (a.s.vonderheydt@uu.nl)

d. Alfred-Wegener-Institut Helmholtz-Zentrum für Polar-und Meeresforschung (AWI) P.O. Box 1201 61, 27515 Bremerhaven, Germany. (pkoehler@awi.de)

\footnotetext{
${ }^{1}$ Joint lead authors

* Corresponding author (eelco.rohling@anu.edu.au)
} 


\begin{abstract}
.
Climate sensitivity represents the global mean temperature change due to changes in the radiative balance of climate, and is studied for both present/future (actuo) and past (palaeo) climate variations. Palaeo-estimates are often considered informative for assessments of actuo-climate change due to anthropogenic greenhouse forcing. But this utility remains debated because of concerns about the impacts of uncertainties, assumptions, and incomplete knowledge about controlling mechanisms in the dynamic climate system with its multiple interacting feedbacks. This is exacerbated by the need to assess actuoand palaeo-climate sensitivity over different timescales, with different drivers, and with different (data and/or model) limitations. Here we visualise these impacts with idealised representations that graphically illustrate the nature of time-dependent actuo- and palaeo-climate sensitivity estimates. Thus, we evaluate strengths, weaknesses, agreements, and differences between the two approaches. This highlights priorities for future research to improve the use of palaeo-estimates in evaluations of current climate change.
\end{abstract}

Keywords: Climate sensitivity; present climate; palaeoclimate; idealised scenarios; feedbacks.

\title{
1. Introduction
}

Studies of past and future climate change often centre on some "climate sensitivity" to changes in the radiative balance of the Earth. It appears in many guises. The equilibrium climate sensitivity (ECS) is the equilibrium global annual mean temperature rise caused by a doubling of atmospheric $\mathrm{CO}_{2}$ concentration (Charney et al 1979, Knutti \& Hegerl 2008, IPCC 2013, Forster 2016, Stevens et al 2016), or a radiative forcing of about $3.7 \mathrm{Wm}^{-2}$ (c.f., Myhre et al 1998, Byrne \& Goldblatt 2014, Etminan et al 2016), which can be further amplified or dampened by a number of feedbacks within the climate system acting on many different timescales (e.g., von der Heydt et al 2016). The amount of global annual mean temperature change in response to a given change in the Earth's radiative balance is either called "climate sensitivity parameter" or "specific climate sensitivity" (in $\mathrm{K} /\left(\mathrm{Wm}^{-2}\right)$ or ${ }^{\circ} \mathrm{C} /\left(\mathrm{Wm}^{-2}\right)$ ). The transient climate response is the global annual mean temperature rise at the time of $\mathrm{CO}_{2}$ doubling; i.e., before the system fully re-equilibrates with the imposed forcing (IPCC 2013).

No matter which definition or timescale is considered, the response (or sensitivity) of climate (or temperature) to a perturbation in the radiative balance (or forcing) is an important metric for evaluating the potential outcomes of anthropogenic impacts on the radiative balance, such as greenhouse-gas releases, land-use changes, and aerosol emissions. The radiative balance, in turn, represents the sum of radiative forcings and feedbacks, where the latter occur over a wide range of timescales (Figure 1), and which collectively determine the surface temperature on Earth. Feedbacks are commonly categorised as "fast" when acting within less than 100 years, or "slow" when acting over longer timescales, although this timescale-based distinction is somewhat blurry in reality (Figure 1) (see overview in PALAEOSENS 2012). 
Attempts at constraining climate sensitivity have been made throughout the past century and before, and despite advances in our understanding of the physical processes that govern the Earth's climate, the estimates have not changed much from the very earliest ones (Arrhenius 1896, Callendar 1938, IPCC 2013, Stevens et al 2016). Current estimates of climate sensitivity remain within a $66 \%$ probability range of $1.5 \mathrm{~K}$ to $4.5 \mathrm{~K}$ (Charney et al 1979, IPCC 2013, Stevens et al 2016). But research into this climate metric has intensified in recent years, notably because of increasing concerns about our future global warming trajectory and implementation of mitigation strategies (Mann 2014). Climate sensitivity has been extensively investigated in modelling studies for both past climates (e.g., Lunt et al 2010) and projections into the future (e.g., Fasullo \& Trenberth 2012, Sherwood et al 2014), while another intensive branch of research is based on climate sensitivity estimates from past climate (palaeoclimate) reconstructions (Hansen \& Sato 2012, PALAEOSENS 2012, Skinner 2012, Royer 2016, von der Heydt et al 2016). An emerging property of recent investigations into present-day ECS is some apparent non-linearity or climate-background-state dependence (Knutti \& Rugenstein 2015). In the typical approach to calculate ECS, extrapolating transient climate simulations following an abrupt doubling of $\mathrm{CO}_{2}$ to the point when surface temperature change becomes zero, it turns out that a linear relationship is not the best approximation (Bloch-Johnson et al 2015), and also the so-called fast feedbacks are still changing after more than 150 years (Rugenstein et al 2016). These are key issues for further research. In addition, there is interest in better understanding climate sensitivity and the forcing and feedback processes that control Earth's climate through past episodes of climate change, such as Plio-Pleistocene glacialinterglacial cycles and earlier Cenozoic events and sustained episodes of global warming. Also in this field, potential state dependence is a key focus.

Palaeoclimate data can be used to evaluate climate sensitivity in several ways, which include the analysis of: (i) time series of the recent past, such as the last millennium (Hegerl et al 2006); (ii) comparing the present (preindustrial) with specific time slices, such as the Last Glacial Maximum (Hansen et al., 1984, Schneider von Deimling et al 2006, Schmittner et al 2011), or Cenozoic intervals that were warmer and had higher-than-preindustrial atmospheric $\mathrm{CO}_{2}$ concentrations (Pagani et al 2010, Hansen et al 2013b, Anagnostou et al 2016); or (iii) multiple climate cycles, such as the repeated alternation between glacial and interglacial periods that characterised the Pleistocene Epoch (Hansen et al 2007, Rohling et al 2012, von der Heydt et al 2014, Köhler et al 2015; Friedrich et al 2016) or the Pliocene (Martinez-Boti et al 2015). These approaches suffer from relatively large uncertainties that are inherent to the use of proxy data, from a shortage of globally distributed datasets of past temperature changes that span the desired timescales, and from problems in obtaining consistent chronologies for the various time series of climate forcing and responses. Regardless, climate sensitivity estimates from palaeoclimate data have the merits of being based on real data and being calculated through a full range of climate states, including those colder and warmer than preindustrial.

Climate sensitivity to changes in climate forcing depends on numerous response (feedback) processes - all with their own (uncertain) timescales (Figure 1) and 
(uncertain) relative radiative contribution, or efficacy (Hansen et al 2005, Bony et al 2006). The conceptual background has been previously discussed, both in relation to modern/future (hereafter referred to as "actuo") climate change and to palaeoclimate change (e.g., Charney et al 1979, Hansen et al 1984, 2005, 2007, 2008, 2013b, Skinner 2012, Marvel et al 2016, von der Heydt et al 2016). In PALAEOSENS (2012), discussions were synthesised, and relationships mathematically evaluated.

Here we outline the PALAEOSENS (2012) framework, and consider its implications as well as challenges. We then formulate some simple, purely theoretical, graphical representations to illustrate and evaluate the nature of the probability distributions for climate sensitivity in response to anthropogenic forcing and through episodes of climate change in the palaeoclimate record. We use these schematic representations to investigate how climate sensitivities from actuo- and palaeo-studies can best be assed to make them comparable to one another. Finally, we consider implications of the results for the potential of narrowing down the climate sensitivity range and/or its dependence on climate background states.

\section{Framework}

PALAEOSENS (2012) outlined an approach that uses reconstructions of key climate parameters in the geological past to approximate the equilibrium fastfeedback climate sensitivity term that applies to actuo-climate studies $\left(S^{a}\right.$; i.e., the equilibrium climate sensitivity calculated when all fast feedbacks and surface ocean warming have completed). The main issue that needed to be addressed in aligning climate sensitivity estimates from palaeoclimate studies with those from actuoclimate studies concerns the contrasting timescales involved - natural climate change is much slower than anthropogenic climate change (Crowley 1990, Zeebe et al 2016). Natural change therefore includes the action of feedbacks that are too slow to be relevant over the next 100-200 years, and/or relate to processes that are not (yet) included in climate models due to computational limits (e.g. continental ice sheets).

One way to address this issue uses the so-called "time-dependent climate sensitivity" approach, which accounts for both fast and slow feedbacks, and which allows evaluation of climate sensitivity continuously over timescales that are relevant both to the imminent future and to the distant geologic past (Zeebe 2013). It builds on the notion that fast and slow feedbacks operate continuously in the climate system, thereby modulating the evolution of climate and its sensitivity to forcing through time. The fast feedback climate sensitivity is set (to $3 \mathrm{~K}$ ), while the evolution of the slow feedbacks (carbon cycle, vegetation, lowlatitude glaciers, and polar ice sheets) is modelled using constraints from the palaeoclimate record. The strength of this approach for future climate projections lies in the comprehensive estimates of anthropogenic warming (and its duration) that it delivers. For example, it accounts for the impacts of warming on the solubility of $\mathrm{CO}_{2}$ in the ocean, which further enhance global warming by increasing atmospheric $\mathrm{CO}_{2}$ concentrations (Zeebe 2013). Note that this approach relies on linearization of the climate response around the background 
climate, and only applies to cases where the climate system (after a very long time) reaches a unique and true equilibrium. In reality, the climate system may instead: $(a)$ exhibit variability on many different timescales (interannual to orbital) with potentially different characteristics under $\mathrm{CO}_{2}$ forcing; and $(b)$ cross tipping points that imply highly nonlinear climate responses (e.g. Drijfhout et al 2015).

Another way, which has been more extensively applied, explicitly resolves radiative forcing due to the slow feedback processes (e.g., ice-sheet albedo, vegetation albedo, and/or greenhouse-gas concentrations), and then removes their influences from the calculated climate sensitivity (Hansen et al 2007, Köhler et al 2010, Masson-Delmotte et al 2010, PALAEOSENS 2012, Rohling et al 2012, Martinez-Boti et al 2015). PALAEOSENS (2012) proposed the parameter $S^{p}$ for palaeoclimate sensitivity in terms of temperature change relative to forcing due to $\mathrm{CO}_{2}$ change only, which is equivalent to their specific climate sensitivity

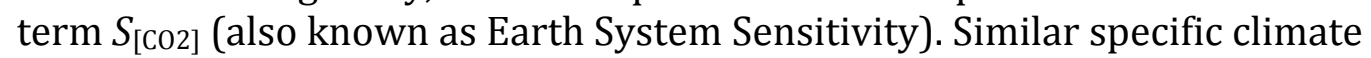
sensitivity terms can be formulated relative to other (combinations of) slow feedback processes; e.g., relative to $\mathrm{CO}_{2}$ and land-ice changes $\left(S_{[\mathrm{CO} 2, \mathrm{LI}]}\right)$, or to changes in overall greenhouse-gas levels, land-ice albedo, and vegetation albedo $\left(S_{[\mathrm{GHG}, \mathrm{LI}, \mathrm{VG}]}\right)$. Conceptually, the PALAEOSENS (2012) approach assumes that $S^{p}$ can be "corrected" for all processes that are either slow or not included in models, such that one ends up with an approximation of $S^{a}$. The subscripts then identify the slow feedbacks that are "corrected" for, or that - in other words - are effectively considered as climate forcings. This is a pragmatic approach that requires knowledge about the radiative impacts of all processes at any moment in the past, which then becomes the real challenge. Here we evaluate comparability between "actuo" and "palaeo" examples, following the PALAEOSENS (2012) approach of focussing on specific radiative contributions of the various processes, since this approach can be relatively easily illustrated in graphical examples.

In more specific terms, PALAEOSENS (2012) argues that the observed relatively low rates of temperature change imply that climate remained close to equilibrium, especially in the preindustrial past. In general, global annual mean temperature changes are small relative to the $288 \mathrm{~K}\left(15^{\circ} \mathrm{C}\right)$ absolute temperature of Earth's surface. Temperature change (warming) over the past several decades amounts to between $0.01 \mathrm{~K} / \mathrm{y}$ (IPCC 2013) and $0.015 \mathrm{~K} / \mathrm{y}$ (Hansen et al 2010). During Pleistocene deglaciations, it was an order of magnitude slower (Masson-Delmotte et al 2010, Shakun et al 2012, Friedrich et al 2016, Snyder 2016), and during the dramatic onset of the Palaeocene-Eocene Thermal Maximum, 56 million years ago, rates of global warming were somewhere in between those two (Zachos et al 2006, Zeebe et al 2009, Kemp et al 2015). Today, climate is affected by an external forcing (notably greenhousegas release) that is increasing faster than all but the fastest climate processes can respond. Thus, the climate remains in a state of disequilibrium until sufficient time has elapsed for the slower processes to adjust, where completion of centennial-scale surface ocean heat uptake is commonly used to denote "equilibrium". Indeed, the "energy imbalance" caused by ocean heat uptake is widely used as a measure of the overall disequilibrium state (e.g., Hansen et al 
$2011,2013,2016)$. During most of the pre-industrial past, climate feedbacks were close to equilibrium with the global temperature, given that these processes themselves were driving the climate changes.

For close-to-equilibrium changes in the past, radiative impacts of the global mean external climate forcings (negligible annual mean global insolation changes), slow feedbacks (including carbon-cycle processes), and fast feedbacks must have been almost, if not precisely, balanced. Hence, $\Delta R_{[s f]}+\Delta R_{[f f]} \approx 0$, where $\Delta R$ stands for radiative change, $s f$ stands for the sum of all (slow feedback) forcings, and $f f$ stands for the sum of fast feedbacks (for more detail, see: PALAEOSENS 2012, von der Heydt et al 2014, von der Heydt \& Ashwin 2016). Thus, for a given (small) temperature change $\Delta T$, the equilibrium fast-feedback climate sensitivity parameter $S^{a}=\Delta T / \Delta R_{[f]]}$ may be approximated by $S_{[s f]}=\Delta T /$ $\Delta R_{[s f]}$. Estimates following this approach throughout the Cenozoic Era consistently fall within a distribution of about of $0.3-1.9$ or $0.6-1.3 \mathrm{~K} /\left(\mathrm{Wm}^{-2}\right)$ at $95 \%$ or $68 \%$ probability, respectively (Köhler et al 2010, Masson-Delmotte et al 2011, PALAEOSENS 2012, Rohling et al 2012, Martinez-Boti et al 2015, Friedrich et al 2016). The latter scales to a warming of 2.2-4.8 K per doubling of atmospheric $\mathrm{CO}_{2}$, in agreement with IPCC estimates (IPCC 2013).

A major question that remains open is whether this distribution reflects: (1) reconstructed climate sensitivity values that are scattered randomly through the range that is determined (i.e. random uncertainty); or (2) - more likely - a combination of different, narrower palaeoclimate sensitivity ranges from different time periods, and in particular from different background climate states, which would therefore represent a "systematic" source of uncertainty (see also Stevens et al 2016, von der Heydt et al 2016). Indeed, model-based process studies and theoretical considerations drive an expectation that the value of climate sensitivity should depend on the prevailing climate background state, as contributing feedback processes may become more or less effective (i.e., their efficacy may change) under different background climate conditions (e.g., Crucifix 2006, von der Heydt et al 2016, for an attempt to define different types of state dependence). Recent work using palaeoclimate observations (von der Heydt et al 2014, 2016, Köhler et al 2015) suggests that state-dependence may be detectable with model-based interpretation of the data, but the matter has not yet been conclusively resolved due to the uncertainties involved in the data and in the (chronological) comparisons between records. In detail, the statedependence identified in Köhler et al (2015) mainly resulted from calculation of the land-ice albedo radiative forcing, $\Delta R_{[\mathrm{LI}]}$, based on deconvolution of the global deep-sea benthic oxygen isotope record with 3D ice-sheet models. Another, relatively minor contribution resulted from latitudinal dependence of changes in incoming insolation, $I$. Combined, these drove a non-linear relationship between $\Delta R_{[\mathrm{LI}]}$ and sea level. Earlier approaches used either simpler 1D ice-sheet models (van de Wal et al 2011), did not similarly account for the latitudinal dependence of $I$ (Köhler et al 2010, PALAEOSENS 2012), or approximated $\Delta R_{[\mathrm{LI}]}$ as a linear function of sea level (Hansen et al 2008, Martinez-Boti et al 2015), and therefore were primed to miss the state-dependence detected by Köhler et al (2015). More recently, a similar non-linear relationship between global temperature change and radiative forcing was found in 784-kyr-long simulation results from an Earth 
system model of intermediate complexity, which also suggests state dependence

A key cause of state dependence of climate sensitivity - especially with respect to slow feedbacks - concerns change in the efficacy of one or more of these feedbacks under different climate states, meaning that the radiative contribution of these processes changes through time. For example, a similar unit area of ice has a stronger radiative impact at lower latitudes than at higher latitudes; i.e., the efficacy of the ice-albedo feedback may be noticeably stronger for lower-latitude ice than for higher-latitude ice. This notion has implications for palaeoclimate sensitivity studies in which maximum versus intermediate glaciation states are considered. In another example, large-scale clustering of continental mass at low latitudes in the Neoproterozoic supercontinent of Rodinia is thought to have amplified the difference between continental reflection and sea-surface absorption of incoming solar radiation, relative to distributions with more continental mass at higher latitudes, which facilitated major global cooling that eventually led to Snowball Earth (Kirschvink 1992), although this influence remains contested (Poulsen et al 2002). But state dependence of climate sensitivity may also result from less obvious changes that - in particular for fast feedbacks - are not necessarily well approximated in terms of efficacy changes. Among these, variations in cloud coverage and types are among the least understood parameters in palaeoclimate studies, even though they likely exerted a major control on both albedo, and retention of outgoing long-wave radiation (e.g., Bony et al 2015, Zhou et al 2016).

So far, it is virtually impossible to develop a comprehensive view of past efficacy changes for most feedbacks. This complicates reconstruction of state dependence in palaeodata-based studies. A pragmatic solution is therefore needed. One approach assumes constant efficacies for all feedbacks, and then assesses whether calculated equilibrium climate sensitivities appear to have been constant or variable with climate background state. Any inferred variations subsequently become targets for investigating potential variability of feedback efficacies. Alternatively, hybrid approaches are possible, in which feedback efficacies through time are assessed with climate models. But this introduces potential model bias into the primarily observation-based estimates, so that subsequent comparisons with model-based results become somewhat circular.

In the next section, we use highly idealised examples to graphically illustrate: (a) the controls on palaeoclimate sensitivity probability distributions; (b) the limitations due to data availability issues that affect approximations of $S^{a}$ using $S_{[s f]}$ in palaeodata-based studies; and (c) how state-dependence due to temporal changes in feedback efficacy may factor into the reconstructed probability distributions.

\section{Actuo- versus palaeo-climate sensitivity}

286 As a first step toward more precise assessments of climate sensitivity,

287 PALAEOSENS (2012) advocated strict adherence to specific definitions, to avoid 288 conflating information that applies over different timescales and different 
climate background states, as tends to occur in broadly generalised approaches (Pagani et al 2010, Snyder 2016). However, while the PALAEOSENS (2012) framework may ensure like-for-like comparisons, it still involves choices and assumptions that may affect the outcome (e.g., Skinner 2012). In consequence, climate sensitivity is more a "moving target" than a unique fixed number, depending on the choices and assumptions made, and on the timescales and climate background states over which it is considered. Also from the point of view of dynamical systems theory, climate sensitivity is more likely a probability distribution than a single number (von der Heydt \& Ashwin 2016), where the distribution arises not from randomness or observational errors, but from the actual climate system dynamics that exhibit state-dependent behaviour through their fast feedback processes. Thus, pertinent questions remain about the extent to which a determination of $S_{[s]}$ may provide insight into the $S^{a}$ that is relevant to anthropogenic forcing. We explore this with simple, schematic and idealised graphic example scenarios.

Different from most modelling approaches to climate sensitivity, we consider here a time-dependent climate sensitivity $S(t)$ to reflect both short-term variations and longer-term background-state dependence of $S$. We follow the general principles laid out before (PALAEOSENS 2012), where $S$ is determined by the radiative balance of the planet and different feedbacks enhance or dampen the initial temperature response:

$S=\frac{\Delta T}{\Delta R}=\frac{-1}{\lambda_{P}+\sum_{i=1}^{N} \lambda_{i}^{f}+\sum_{j=1}^{M} \lambda_{j}^{S}}$

Here the $\lambda$ terms refer to the strength of different feedback processes (in terms of a "feedback factor," in $\mathrm{Wm}^{-2} \mathrm{~K}^{-1}$ ), sorted by the time scale on which they act: $\lambda_{P}$ reflects the change in long-wave radiation in the absence of other feedbacks (the so-called "Planck" feedback), and superscripts $f$ and $s$ denote $N$ fast and $M$ slow feedback processes, respectively. Note that equation (1) includes the sum of slow feedbacks (third term in the denominator), which is the version applicable for calculating palaeo-climate sensitivity in the PALAEOSENS (2012) framework. For actuo-climate sensitivity, that sum of slow feedbacks is omitted from the denominator.

Generally, feedback factors are assumed to be constant. However, to reflect state dependence of feedbacks, a time-dependent climate sensitivity $S(t)$ results from the fact that both $\lambda f$ and $\lambda^{s}$ can be time dependent. For example, state dependence of fast feedback processes as inferred between glacial and interglacial periods (von der Heydt et al 2014) may be represented by a (long time-scale) variation of $\lambda f(t)$. The different response times in all feedback factors can be reflected by a delayed growth of the feedback factors for those processes with slower timescales. First details in this direction were published by Zeebe (2013), where the slow feedback processes $\left(\lambda^{s}\right)$ were assumed to grow from zero to their full strength after a certain time delay. 
We adopt a similar approach with focus on changes in the time-domain. However, our schematic scenarios build up the argument in terms of simple prescribed functions for the radiative contributions $(\Delta R)$ from the various processes, rather than in terms of feedback responses. This is done because we aim to graphically compare palaeo- with actuo-scenarios, and for palaeoscenarios the data more directly resolve $\Delta R$ contributions (Hansen et al 2007, 2008, Köhler et al 2010, Masson-Delmotte et al 2010, Rohling et al 2012).

Our actuo-scenario (section 3.1) and palaeo-scenario (section 3.2) represent processes that control changes in the radiative balance of climate by means of simple prescribed sigmoidal response functions, with random, uniformly distributed, uncertainty ranges that are evaluated in a Monte-Carlo-style approach of 1000 separate instances. Each response function describes a schematic time-dependent development of a radiative anomaly, in which a phase of exponentially increasing growth from zero is followed (in a symmetrical manner through time) by a phase of exponentially decreasing growth until settling at the stipulated maximum radiative impact of the process considered. The various response functions are then summed up, giving a median record of total radiative change over time, and an uncertainty range, based on percentile ranges across all Monte-Carlo instances. A rough scaling is worked out for each instance to calibrate the record of total radiative change to one of total temperature change over time. This temperature record is then used in a ratio relative to the records for component sums $\Delta R_{[f f]}$ and $\Delta R_{[s f]}$, to estimate the implied $S^{a}$ and $S_{[s f]}$, respectively.

Although our radiative response functions are simple prescribed functions rather than fully interactive feedback processes, we aim to use reasonably realistic amplitude scalings (efficacies) for the contributing radiative (feedback) processes in both the actuo- and palaeo-scenarios, based on published numbers for modern climate and for Pleistocene glacial-interglacial cycles. Yet we emphasise that the scenarios may not be viewed as in-depth analyses, since they do not comprehensively represent the interactive physics of the climate system. Including the latter would deeply entangle the idealised results shown here, and confound relationships between the various climate sensitivity definitions and their underlying processes. This would make it more difficult to visualise the potential impacts of issues such as limited data availability, unknown past processes, and fundamental uncertainties. Our idealised example scenarios guide the discussion by visualising such impacts (sections 4.1 and 4.2). Finally, given that our approach - which draws on proxy-based palaeo-reconstructions of radiative forcing anomalies $(\Delta R)$ to calculate temperature change $(\Delta T)$ and climate sensitivity $(S)$ - may be less familiar to climate modellers, we end the discussion with an illustration of how the importance of the time-domain might be addressed in a feedback-focussed analysis framework (section 4.3).

\subsection{Illustrative scenario for actuo-climate sensitivity}

For the actuo-climate scenario, we consider that - for any given trigger (e.g., greenhouse-gas emissions) - a sequence develops of delayed temperature responses (indicated with $\delta$ ) and radiative feedback responses (indicated with $\Delta R$ ), all with their own timescales and amplitudes. Key responses to be taken into 
account are the direct warming effect of the emissions, the associated outgoing long-wave radiation cooling response (the Planck response), and other typical "very fast feedbacks" that include changes in water-vapour content, atmospheric lapse-rate, and cloud albedo. All of these operate quasi-immediately and are here rolled into one term that also includes the impact of a single greenhouse gas introduction within the first year $\left(\Delta R_{[\text {T2] }]}\right)$, since separating these impacts is not needed for the simple scenarios considered.

We scale the total of the initial forcing to $3.7 \mathrm{Wm}^{-2}$, based on the sum of the modern effective climate forcings for $\mathrm{CO}_{2}, \mathrm{CH}_{4}, \mathrm{CFCs}, \mathrm{N}_{2} \mathrm{O}$, and $\mathrm{O}_{3}$ through 2015 (Hansen et al 2016) (Figure 2). Note that this is different in nature - but confusingly similar in magnitude - to common estimates given for the radiative forcing of a doubling of $\mathrm{CO}_{2}$ concentrations. We assign to this forcing a uniformly distributed uncertainty range of $\pm 10 \%$ to span the reported $\pm 0.3 \mathrm{Wm}^{-2}$ range of observations (Figure 2). We partition this $3.7 \mathrm{Wm}^{-2}( \pm 10 \%)$ in a simple manner, into: $(a)$ a virtually instantaneous response of $60 \%\left(\Delta R_{[\mathrm{T} 2]}=2.2 \mathrm{Wm}^{-2}\right)$ in year 1 ; (b) a somewhat slower response of (arbitrarily set) $10 \%$ due to snow and sea-ice albedo adjustment over a few decades $\left(\Delta R_{[\mathrm{SSI}]}=0.4 \mathrm{Wm}^{-2}\right)$; and $(c)$ a delayed temperature response of $30 \%$ caused by surface ocean and deep ocean heat uptake $\left(\delta_{[\mathrm{SO}]}+\delta_{[\mathrm{DO}]}=1.1 \mathrm{Wm}^{-2}\right)($ Table 1$)$. The latter is based on an observed cumulative ocean heat uptake of about $125 \times 10^{21} \mathrm{~J}$ between 2000 and 2010 (IPCC 2013, Whitmarsh et al 2015). We simply partition this 50:50 between surface and deep, although in reality the observed (and CMIP5 simulations confirmed) cumulative ocean heat uptake over the industrial era is unequally distributed, with about $33 \times 10^{22} \mathrm{~J}$ in the upper $700 \mathrm{~m}$ of the ocean, and $10 \times 10^{22} \mathrm{~J}$ and $7 \times 10^{22} \mathrm{~J}$ in 700-2000m and deeper, respectively (Gleckler et al 2016). The final fast feedback considered $\left(\Delta R_{[\mathrm{AE}]}\right)$ involves the albedo impacts of aerosol and landsurface changes, with timescales up to a few decades. We scale $\Delta R_{[\mathrm{AE}]}$ to -1.2 $\mathrm{Wm}^{-2}$ based on the effective climate forcing of aerosol and surface albedo through 2015 (Hansen et al 2016), and we capture the reported uncertainties with a generous, uniformly distributed, uncertainty range of $\pm 50 \%$ (Figure 2; Table 1). Note that, by including the present-day effect of aerosols, our approach is not easily comparable with GCM-based results for ECS (typically obtained from $2 \mathrm{xCO}_{2}$ experiments), since aerosol impacts are not commonly included in those simulations. But aerosols are an important aspect of real-life climate change, and ignoring them would skew results.

The fast responses $\Delta R_{[\mathrm{T} 2]}, \Delta R_{[\mathrm{SSI}]}$, and $\Delta R_{[\mathrm{AE}]}$, are followed by the influences of delayed surface-ocean (upper $2000 \mathrm{~m}$ ) heat uptake $\left(\delta_{[\mathrm{so}]}\right)$ and carbon-cycle feedbacks such as permafrost or wetland releases of methane $\left(\Delta R_{[\mathrm{CFB}]}\right)$, over timescales of up to a few centuries. Then follow even slower responses, related to deep-ocean (> $2000 \mathrm{~m}$ ) heat uptake over a millennium or two $\left(\delta_{[\mathrm{DO}]}\right)$, albedo changes due to large-scale reorganisations of vegetation that may occur over many centuries $\left(\Delta R_{[\mathrm{VG}]}\right)$, and multi-century to millennial-scale (Grant et al., 2014) continental ice-sheet albedo adjustments $\left(\Delta R_{[\mathrm{LI}]}\right)$. The amplitudes of $\delta_{[\mathrm{SO}]}$ and $\delta_{[\mathrm{DO}]}$ were discussed above, $\Delta R_{[\mathrm{CFB}]}$ is arbitrarily set to $5 \%$ of $\Delta R_{[\mathrm{T} 2]}$, and $\Delta R_{[\mathrm{VG}]}$ is arbitrarily set to $5 \%$ of the sum $\Delta R_{[\mathrm{T} 2]}+\Delta R_{[\mathrm{AE}]}$. Both $\Delta R_{[\mathrm{CFB}]}$ and $\Delta R_{[\mathrm{VG}]}$ are assigned uniformly distributed uncertainty ranges of $\pm 50 \%$. 
For $\Delta R_{[\mathrm{Ll}]}$, we rely on suggestions that - as long as $\mathrm{CO}_{2}$ levels remain well below about 750 ppm (DeConto \& Pollard 2016) - ice-sheet changes affect sea levels up to about $20 \mathrm{~m}$ above the present (Foster \& Rohling 2013, Rohling et al 2013, Gasson et al 2016). We use a median adjustment of $10 \mathrm{~m}$ sea-level rise for our scenario, in agreement with peak values for the previous (Eemian) interglacial when temperatures rose to around $1^{\circ} \mathrm{C}$ above present (see discussions in Hansen et al 2013a, 2016, Hoffman et al 2017). Reconstructions for palaeoscenarios infer that the radiative impacts of ice-sheet decay equal about $3 \mathrm{Wm}^{-2}$ per 125 m equivalent sea-level rise (Hansen et al 2008, Köhler et al 2010, Rohling et al 2012). There remains considerable uncertainty with this number. Using 3D ice-sheet models, Köhler et al (2015) find $4 \mathrm{Wm}^{-2}$. Friedrich et al (2016) report only $1.5 \mathrm{Wm}^{-2}$, likely related to a smaller simulated albedo change between land-ice-covered conditions and no-ice conditions relative to that used in Köhler et al (2015). We use a uniformly distributed uncertainty of $\pm 50 \%$ to $\Delta R_{[\mathrm{LI}]}$, to allow a uniform range between 1.5 and $4.5 \mathrm{Wm}^{-2}$ for a $125-\mathrm{m}$ equivalent sea-level change, which spans the estimates in the literature. Hence, we set the median $\Delta R_{[\mathrm{LI}]}$ in the actuo-scenario to $3 \times(10 / 125) \mathrm{Wm}^{-2}$, for sea-level rise up to $+10 \mathrm{~m}$. We accept that use of this linear approximation of $\Delta R_{[\mathrm{LI}]}$ from sea-level change obscures a potentially important non-linearity of the climate system, which may underpin state-dependence in $S_{[\mathrm{CO}, \mathrm{LI}]}$ over the last $2 \mathrm{Myr}$ (Köhler et al 2015).

For each process, the aforementioned idealised signal-development curve uses the standard functional form

$$
\Delta R(t)=\frac{\left(h+\varepsilon_{h}\right)}{1+\mathrm{e}^{\left\{-c\left(\frac{t}{\tau+\varepsilon_{\tau}}-\phi\right)\right\}}}
$$

Here $h$ is the total signal amplitude (Table 1, with range as stated), $t$ is time, $\tau$ is the timescale of full response (Table 1 , with range as stated), $\phi$ is a translation constant (set to 0.5 ) to ensure that signals start at $t=0$, and $c$ is an acuteness constant (set to 14) to ensure that full signal amplitude is achieved over timescale $\tau$. We run equation (2) for each process in a Monte-Carlo-style manner $(\mathrm{n}=1000)$, with random perturbations over the uniformly distributed uncertainty ranges to both $h$ and $\tau$ ( $\varepsilon_{h}$ and $\varepsilon_{\tau}$ in Table 1 ). Note that we chose uniform distributions because the uncertainties do not so much represent standard random error distributions around a mean, as ranges within which parameter values may systematically shift (efficacy changes) in relation to changes in the climate background state. We then add all instances up across all processes to yield the cumulative radiative response, and determine the median along with the $2.5^{\text {th }}$ and $97.5^{\text {th }}$ percentiles that delineate the $95 \%$ probability bounds (Figure $3 \mathrm{a}$ - note that probability bounds are only shown for the cumulative total, to avoid clutter).

Next, we roughly scale the cumulative radiative response distribution, $\Delta R_{[\text {tot }]}(t)$, to a distribution of total temperature change through time, $\Delta T(t)$ (Figure $3 \mathrm{~b}$ ), assuming a constant amount of temperature change per $\mathrm{Wm}^{-2}$ of radiative change, regardless of the process. A rough scaling is sufficient because we are not attempting to model reality, but only to create a graphic illustration scenario. 
Our approach scales each individual Monte-Carlo instance's sum of completed radiative contributions by fast forcings/feedbacks $\left(\Delta R_{[f f]}=\Delta R_{[\mathrm{T} 2]}+\Delta R_{[\mathrm{SSI}]}+\right.$ $\left.\Delta R_{[\mathrm{AE}]}\right)$ at the time-point of calibration ( $t_{c a l}$, where all fast responses are completed; blue bar in Figure 3a), to a prescribed temperature change, $\Delta T_{\text {tcal. }}$ In the actuo-scenario, $\Delta T_{\text {tcal }}$ is randomly drawn from a normal distribution with a mean of $1^{\circ} \mathrm{C}$ and $1 \sigma$ of $0.1^{\circ} \mathrm{C}$, in approximation of the current amount of global warming in response to the net radiative change due to forcing (greenhouse-gas emissions) and fast feedbacks (Hansen et al 2016, 2013a, IPCC 2013). This yields $s_{\text {tcal }}=\Delta T_{\text {tcal }} / \Delta R_{[f f]}$ tcal, which in turn gives the time-series of temperature change using $\Delta T(t)=\Delta R_{[\operatorname{tot}]}(t) \times s_{t c a l}$, with propagation of all uncertainties in the various $\Delta R$ terms and in $\Delta T_{\text {tcal }}$ across all Monte-Carlo instances (Figure $3 \mathrm{~b}$ ).

We now have $\Delta R_{[f]}(t)$ and $\Delta T(t)$ (Figure 3a,b). This allows estimation of timedependent climate sensitivity parameter $S(t)=\Delta T(t) / \Delta R_{[f f]}(t)$ (Figure 3c). Because $\Delta T(t)$ develops in response to the action of all forcings/feedbacks $\left(\Delta R_{[\mathrm{tot}]}(t)=\Delta R_{[f f]}(t)+\Delta R_{[s]}(t)\right)$, while $S(t)$ depends only on $\Delta R_{[f]]}(t)$, the reconstruction of $S(t)$ continues to vary after completion of the fast processes. The conceptual "equilibrium" value $S^{a}$ is achieved when surface-ocean warming has completed, while slow feedbacks have not yet become important (PALAEOSENS 2012), hence $S^{a}$ is best identified at $t=200 \mathrm{y}$ in our scenario. Its range reflects propagation of all uncertainties in all input variables, and we constrain $95 \%$ probability bounds using $2.5^{\text {th }}$ and $97.5^{\text {th }}$ percentiles across all 1000 instances. Histograms for $S^{a}$ are given in red in Figure 4.

However, there is a complication. By $t=200 \mathrm{y}$, the scenario's relatively rapid carbon-cycle feedbacks $\left(\Delta R_{[\mathrm{CFB}]}\right)$ have come into play. This illustrates the complexity of using a stationary definition to diagnose a complex, dynamic, and interconnected system. At $t=200$, we therefore read values of $S^{a}$ calculated with (dashed red in Figure 4) and without (solid red in Figure 4) explicitly accounting for $\Delta R_{[\mathrm{CFB}]}$. While possible in our simple scenario, explicitly accounting for $\Delta R_{[\mathrm{CFB}]}$ is difficult in reality because it requires knowledge of the proportion of carbon derived from feedbacks, relative to that of anthropogenic external carbon input into the climate system. Hence, the solid red line in Figure 4 is more relevant practically. The real climate system contains more of such processes, including changes in oceanic carbon uptake efficiency in response to changes in the oceanic temperature and carbon cycle: our simple scenario illustrates the impacts of such issues, but is not all-inclusive.

$S^{a}$ at about $t=200 \mathrm{y}$ still does not reflect the actuo-scenario's full development in response to the initial forcing discussed above. Even without further external forcing, temperature continues to change (first increase, then decrease) because the impacts of slow processes come into play. In our scenario, the key slow processes $\left(\delta_{[\mathrm{DO}]}, \Delta R_{[\mathrm{VG}]}\right.$, and $\left.\Delta R_{[\mathrm{LI}]}\right)$ reach completion after about 1000 years (for the land-ice-volume component in reality, this may be too fast, given that adjustment over $\sim 3000$ years has been suggested by modelling studies; Clark et al 2016). From about $t=3000$ years, carbonate compensation becomes a player as the first of the very slow Earth system responses (eventually including also weathering) that slowly remove the carbon. We portray the "peak" value of $S(t)$ (here named $S^{\max }$ ) using the distribution between $t=1000$ to $3000 \mathrm{y}$. Results are 
presented as solid/dashed blue histograms in Figure 4 (without/with explicitly accounting for $\Delta R_{[\mathrm{CFB}]}$, respectively). If the $\Delta R_{[\mathrm{LL}]}$ adjustment time were stretched to $\sim 3000$ years (cf., Clark et al 2016), $S^{\max }$ would be a narrower peak of similar amplitude, centred on $t=3000 \mathrm{y}$.

\subsection{Illustrative scenario for palaeo-climate sensitivity}

Palaeo-climate sensitivity is approached differently. It relies on quantification of the slow feedbacks; notably those associated with carbon-cycle changes as expressed in greenhouse-gas records $\left(\Delta R_{[\mathrm{GHG}]}\right)$, with continental land-ice albedo changes $\left(\Delta R_{[\mathrm{LI}]}\right)$, and with vegetation-albedo changes $\left(\Delta R_{[\mathrm{VG}]}\right)$. As outlined before, these slow feedbacks are effectively considered as forcings, and their sum $\left(\Delta R_{[s f]}\right)$ is used to approximate the sum of fast feedbacks $\left(\Delta R_{[f f]}\right)$. The development with time in palaeo-climate sensitivity is then estimated as $S_{[s][}(t)=\Delta T(t) / \Delta R_{[s]}(t)$. Within that time-series, equilibrium palaeo-climate sensitivity is identified as $S_{[s f}$, and is reached after all slow feedbacks have reached completion.

Conceptually, no immediate agreement might be expected between actuo- and palaeo-climate sensitivity estimates because they are determined from processes operating over very different time scales, with different assumptions and uncertainties. For example, past climate variations were not adjustments to very rapid, high-amplitude perturbations along the lines of actuo-climate adjustments, but were triggered by slowly developing processes such as orbital forcing, with timescales of many thousands of years. Hence, palaeoclimate records reflect co-evolving changes in all climate-regulating processes (bar the very slowest ones, such as plate-tectonics) either in, or near to, equilibrium with the changing forcing. In consequence, most studies based on time-series of temperature and slow-feedback change directly find the equilibrium value $S_{[s f]}$, although this may not be true in highly resolved studies over centennial-tomillennial-scale climate fluctuations (see below). In addition, palaeoclimate records represent an integration of all feedback processes; e.g., not only is the temperature response to $\mathrm{CO}_{2}$ changes included, but also the $\mathrm{CO}_{2}$ response to temperature changes. Our simple palaeo-scenario allows such complications to be teased apart, to gauge over what timescales signals need to be considered to approximate the desired "equilibrium sensitivity", and what the consequences would be of pushing reconstructions from palaeodata into shorter timescales.

For scale and duration of the processes in our palaeo-scenario, we draw on studies of glacial cycles of the last 800,000 years. As such, this scenario may be seen as a rough approximation of a deglaciation. Deglaciations were triggered by orbital forcing of climate, and in particular by changes in northern hemisphere summer insolation (Hays et al 1976). Orbital forcing involves minor annualmean global-mean forcing $\left(<<0.5 \mathrm{Wm}^{-2}\right)$, but sets up considerable gradients on spatial (latitudinal) and seasonal scales. For very long, it was not exactly understood how these triggered deglaciations (Shackleton 2000, Denton et al 2010, Abe-Ouchi et al 2013), although the timing relationship was reasonably clear (Hays et al 1976, Cheng et al 2016). Recently, a simple model has related every deglaciation of the last one million years to the crossing of summer insolation through a simple threshold (Tzedakis et al 2017). 
Our palaeo-scenario considers an idealised sequence of events inspired by data for the penultimate glacial termination (Marino et al 2015, Holloway et al 2016) because this termination avoids the greater complexity of the last deglaciation, yet still has the requisite chronological control for the relevant climate records (Billups 2015, Marino et al 2015). Following the initial perturbation (orbital forcing) and fast responses, continental ice-volume changes over thousands of years drove the further feedback responses mainly through bipolar temperature see-saw processes (Stocker 1998, Stocker \& Johnsen 2003) that led to rapid Southern Ocean warming and sea-ice reduction, $\mathrm{CO}_{2}$ outgassing, warming and vapour feedbacks, etc. Here we include aerosol changes in that suite as well, despite a lack (so far) of unequivocal empirical evidence of that particular coupling. There is no unambiguous empirical evidence about the phase relationship of global mean vegetation responses to ice-volume changes, either. But given that we seek only to formulate an illustrative, idealised scenario, we simply assume that key vegetation changes take place within centuries following land-ice changes.

The orbital-forcing component is ignored here because of our focus on annualmean global-mean forcing. But it is important in that it triggers feedback responses in the climate system that start directly when climate begins to change; some develop rapidly and others develop slowly. For example, small, regionally/seasonally focussed warming due to orbital forcing triggers sea-ice retreat as well as changes in surface albedo and air-sea carbon exchange, which drive further warming, etc. Thereafter, the slow feedbacks come into action, such as land-ice and vegetation albedo changes. When that happens, fast processes keep interacting with slow feedbacks. Palaeo-reconstructions cannot distinguish fast responses associated with slow processes from the slow processes themselves, or indeed the acceleration of slow processes due to associated, superimposed fast responses. Note that similar interactions occur in actuoclimate changes, but our simple actuo-scenario avoids this issue by pragmatically viewing the stipulated slow feedback influences as effective net impacts. Doing so in the palaeo-scenario would divorce our scenario too much from the palaeoreconstructions, in which temperature (and fast feedbacks) closely co-evolve over thousands of years with the slow feedbacks (e.g., Rohling et al 2009, Grant et al 2012, Grant et al 2014). Because our simple palaeo-scenario cannot resolve such interactions (a dynamic model would be needed), we instead include a crude representation by evaluating the contribution of fast feedbacks to palaeoclimate change as a two-staged development. One stage stands for the initial responses (indicated in Table 2 with $i$ in the parameter names), and the other is the subsequent fast-feedback response (indicated with $r$ ) associated with development of the dominant slow continental land-ice feedback $\left(\Delta R_{[\mathrm{LI}]}\right)$. We tentatively set 0.15:0.85 proportionalities for this, respectively. The proportionality is crudely inspired by early (initial) $\mathrm{CO}_{2}$ jumps that pre-date significant ice volume/sea level responses, at around 16.3, 14.8, and 11.7 thousand years ago, with $\mathrm{CO}_{2}$ levels in each case jumping abruptly by about $15 \%$ of the total deglacial change (Lambeck et al 2014, Marcott et al 2014).

To obtain $S_{[s f]}$, slow feedbacks are effectively considered as climate forcings in the PALAEOSENS (2012) framework. Our scenario considers the total 
greenhouse-gas forcing component $\Delta R_{[\mathrm{GHG}]}$. In palaeodata studies, this can be determined from records of greenhouse-gas changes (notably from ice cores). These integrate all carbon-cycle feedbacks, including carbonate compensation and weathering, which therefore need not be considered separately. We then add the continental land-ice albedo effect, which can be found from sea-level reconstructions, giving $\Delta R_{[\mathrm{GHG}]}+\Delta R_{[\mathrm{LI}]}$. Finally, the slow vegetation-albedo feedback $\left(\Delta R_{[\mathrm{VG}]}\right)$ should be similarly accounted for, but this is substantially challenged by an absence of good, global data coverage, which definitely needs addressing through future research. To date, hardly any palaeostudies have accounted for $\Delta R_{[\mathrm{VG}]}$ (Friedrich et al (2016) is an exception), and we assess the implications by showing results that either include or exclude $\Delta R_{[\mathrm{VG}]}$.

We roughly "calibrate/scale" our palaeo-scenario on the basis of values for the radiative forcings and feedbacks compiled by Rohling et al (2012) and (Köhler et al 2010) (Table 2), with a total median value of $3 \mathrm{Wm}^{-2}$ for $\Delta R_{[\mathrm{LI}]}$ (see section 3.1 for discussion) and $2.5 \mathrm{Wm}^{-2}$ for $\Delta R_{[\mathrm{GHG}]}$. We use $\Delta R_{[\mathrm{VG}]}=1 \mathrm{Wm}^{-2}$, in agreement with Friedrich et al (2016). We assume that the PALAEOSENS (2012) assumption that $\Delta R_{[f]}$ is proportional $\Delta R_{[s]]}$ holds true over timescales of more than a few thousand years. On shorter timescales, it cannot be correct since fast feedbacks dominate at first, while slow feedbacks become important at a later stage (our results illustrate this). Proportional contributions of individual fast responses are irrelevant here because our assessment always considers their summed value, but just for illustration's sake we have made an attempt at reasonably apportioning them (Table 2). The total median range of $\Delta R_{[\mathrm{AE}]}$ is estimated at around $1.5 \mathrm{Wm}^{-2}$, and for snow and sea-ice albedo we use $\Delta R_{[\mathrm{SSI}]}=2$ $\mathrm{Wm}^{-2}$, based on discussions in Rohling et al (2012) and (Köhler et al 2010). This leaves $3 \mathrm{Wm}^{-2}$ for the outgoing long-wave radiation response, water-vapour content, atmospheric lapse-rate, cloud albedo, etc. (all captured within one term, $\left.\Delta R_{[\mathrm{T2}]}\right)$. All radiative terms are assigned $\pm 50 \%$ uncertainties using uniform distributions. The palaeo-scenario omits $\delta_{[\mathrm{SO}]}$ and $\delta_{[\mathrm{DO}]}$ because palaeodata only yield total temperature response, which includes these factors.

The median and $95 \%$ uncertainty limits $\left(2.5^{\text {th }}\right.$ and $97.5^{\text {th }}$ percentiles $)$ are determined from our Monte-Carlo statistics $(\mathrm{n}=1000)$ for the sum of all completed forcings/feedbacks $\left(\Delta R_{[\mathrm{tot}]}=\Delta R_{[f f]}+\Delta R_{[s f]}\right)$ (Figure 5a). From this, we determine $\Delta T(t)$ (Figure $5 \mathrm{~b}$ ), assuming a constant amount of temperature change per $\mathrm{Wm}^{-2}$ of radiative change. To do so, we scale each Monte-Carlo instance's sum of all completed radiative contributions $\left(\Delta R_{[\text {tot }]}\right)$, taken at $t_{\text {cal }}=$ $10,000 \mathrm{y}$ (blue bar in Figure $5 \mathrm{a}$ ), to a temperature change $\Delta T_{\text {tcal }}$. The latter is randomly drawn from a normal distribution set to a mean of $5^{\circ} \mathrm{C}$ and $1 \sigma$ of $1^{\circ} \mathrm{C}$. This gives $s_{\text {tcal }}=\Delta T_{\text {tcal }} / \Delta R_{\text {[tot] tcal }}$, and thus the temperature time series $\Delta T(t)=$ $\Delta R_{[\mathrm{tot}]}(t) \times S_{\text {tcal }}$, with propagation of all uncertainties in the various $\Delta R$ terms and in $\Delta T_{\text {tcal }}$ across all Monte-Carlo instances (Figure $3 \mathrm{~b}$ ). The final range of temperature uncertainties (Figure $5 \mathrm{~b}$ ) spans the entire range of proposed, and still debated, glacial-interglacial temperature-change estimates of Margo (2009), Annan and Hargreaves (2013), Schmittner et al (2011), Rohling et al (2012), Hansen et al (2007), Köhler et al (2010), Masson-Delmotte et al (2010), and Snyder (2016). 
Based on the time-series $\Delta R_{[f f]}(t), \Delta R_{[s f]}(t)$, and $\Delta T(t)$, we calculate $S_{[s f]}(t)=\Delta T(t)$ / $\Delta R_{[s f]}(t)$ as per PALAEOSENS (2012), as well as $S_{[f f]}(t)=\Delta T(t) / \Delta R_{[f]}(t)$, which is more directly comparable to $S^{a}$ from the actuo-scenario (Figure $5 \mathrm{c}$ ). Comparison between $S_{[s f]}(t)$ and $S_{[f]}(t)$ highlights the controls on their similarities and differences. Note that calculating $S_{[f]}(t)$ is possible in this simple scenario, but not in real palaeodata studies. There also is a complication, in that part of $\Delta R_{[s f]}$ consists of $\Delta R_{[\mathrm{VG}]}$, which is still poorly understood in real palaeodata studies. Hence, most of such studies use a pragmatic approximation of $\Delta R_{[s f]}$, which is just $\Delta R_{[\mathrm{GHG}]}+\Delta R_{[\mathrm{LI}]}$. Here we determine both versions, one with and one without $\Delta R_{[\mathrm{VG}]}$, to illustrate how this limitation affects results.

Results for $S_{[s]}(t)$ and $S_{[f f]}(t)$ only begin to fully converge at around $t=5000 \mathrm{y}$ (Figure 5c). This results from a predominance of the fast feedbacks on short timescales, and increased relative importance of slow feedbacks on longer timescales. We read estimates for equilibrium palaeo-climate sensitivity parameter $S_{[s f]}$ as the average of values between $t=8000$ and $t=10,000$ years. Histograms are shown in Figure 6 . The exact convergence between $S_{[s]}(t)$ and $S_{[f f]}(t)$ in the scenario with $\Delta R_{[s]}=\Delta R_{[\mathrm{GHG}]}+\Delta R_{[\mathrm{LI}]}+\Delta R_{[\mathrm{VG}]}$ results from the PALAEOSENS (2012) argument that $\Delta R_{[f f]}$ approximates $\Delta R_{[s f]}$. However, Figures $5 \mathrm{c}$ and 6 show that the common pragmatic limitation of $\Delta R_{[\mathrm{sf}]}=\Delta R_{[\mathrm{GHG}]}+\Delta R_{[\mathrm{LI}]}$ (without $\Delta R_{[\mathrm{VG}]}$ ) will overestimate long-term values for $S_{[s f]}(t)$.

\section{Discussion}

\subsection{Comparison between $S^{a}$ and $S_{[s f]}$}

It stands out strongly from Figure 3 for the actuo-scenario that any reported $S^{a}$ value needs to be carefully referenced to the processes that are included. Commonly, this is done using a rather arbitrary timescale of 100 years, which is then considered to give the equilibrium climate sensitivity that includes all fast processes and surface ocean warming, but excludes slow processes (PALAEOSENS 2012). It is interesting, however, to compare this approach with models, where one can check when equilibrium is reached. For example, Hansen et al (2011) show that, in the GISS ModelE-R, surface-ocean equilibration to instantaneous forcing is just $60 \%$ complete after 100 years, only reaching $\sim 100 \%$ after as much as 2000 years (their Figure 3). In addition, in runs longer than 100 years in most models, the relationship between energy imbalance and temperature change that is used to extrapolate ECS (the so-called Gregory method; Gregory et al 2004) breaks down from an assumed linear relationship to a non-linear one (Bloch-Johnson et al 2015, Rugenstein et al 2016). In addition, as mentioned earlier, any comparison of our number for $S^{a}$ with GCM-based ECS estimates is complicated by the fact that model simulations typically start with a perturbation of $\mathrm{CO}_{2}$, but omit the observed negative radiative impacts from anthropogenic aerosol/land surface changes (Figure 2), which act to reduce the temperature rise.

Clearly, even our simple scenario does not neatly separate processes in time. Uncertainties in the various processes' timescales, and potential operation of 
$\Delta R_{[\mathrm{CFB}]}$ on similar timescales to $\delta_{[\mathrm{SO}]}$, make climate sensitivity a moving target through time (Figure 3 ). For the example set up here, $t=200$ years seems more suitable for determining $S^{a}$ because all included responses (fast feedbacks) have completed (although this is not fully the case in the more realistic model of Hansen et al 2011). However, even in our simple scenario, " $t=200 \mathrm{y}$ " does not provide a clear-cut criterion because the estimate then includes $\Delta R_{[\mathrm{CFB}]}$, which then should be corrected for to match the definition of equilibrium climate sensitivity (Figures 3c and 4). And in reality, there will be further carbon-cycle processes causing similar issues, as discussed in section 3.1. So, while exact definitions of included processes, and better determination of the timescales of the different contributing response functions, are needed to obtain $S^{a}$ estimates that are as precise as possible (and as comparable between studies as possible), it is not obvious that such a level of distinction will always be possible in a natural system.

Figure 3c also shows that, if an arbitrarily selected cut-off time for $S^{a}$ assessment causes partial inclusion of ongoing slow processes (e.g., surface ocean warming), then this may cause extended tails to the probability distribution function (pdf) of the climate sensitivity estimate. Especially if this pdf were made by collating information from different climate models, each with different representations of the myriad processes and their timescales, then the combined pdf may become very broad. A narrower combined pdf might be obtained by identifying the contributions of each process to climate sensitivity in each model, and to then compare results not at a certain time-step, but instead at a certain well-defined point that is based on exactly which processes are included and which are not. This point may occur at different time-steps in different models. This would be a more process-oriented manner of comparing between models than a simple comparison between their results at an arbitrarily selected moment in time, where different processes contribute to different degrees in different models. Also note that our use of uniform distributions for the various parameter uncertainties limits the potential skew and the potential for long tails in the calculated final pdfs (Figure 3), relative to results based on ratios between of gaussian-shaped pdfs for $\Delta T$ and $\Delta R$ (Köhler et al 2010). We consider our approach justified by the fact that most uncertainties concern not random error around mean estimates, but ranges of potential systematic (e.g., state dependent) shifts of the means for many feedback efficacies. In reality, the uncertainty ranges may be more complicated, combining both systematic and random components.

Now we get to the critical question about which process-based definitions would be needed for best comparison of $S^{a}$ from actuo-studies with $S_{[s f]}$ in palaeostudies. One issue concerns the aforementioned impacts of relatively fast carboncycle feedbacks ( $\Delta R_{[\mathrm{CFB}]}$, and similar additional ones in reality; see section 3.1$)$ on how $S^{a}$ is estimated in actuo-studies. In addition, Figures $5 \mathrm{c}$ and 6 illustrate how a lack of explicit accounting for $\Delta R_{[\mathrm{VG}]}$ in the most commonly used specific palaeo-climate sensitivity term $\left(S_{[\mathrm{GHG}, \mathrm{LI}]}\right)$ risks a considerable overestimate of the inferred climate sensitivity value (almost 20\% in our simple scenario), making it an inaccurate approximation of $S_{[f f}$, and therefore $S^{a}$. This clearly illustrates why 
resolving vegetation-albedo impacts on the radiative balance of climate needs priority in data-based reconstructions of palaeo-climate sensitivity.

Next, Figure 5c suggests that - regardless of the definition used - pushing palaeo-climate sensitivity reconstructions from time-series of palaeodata to temporal resolutions of less than 5000 years may result in overestimates of palaeo-climate sensitivity, because of transient behaviour in the solution. This suggests that palaeo-climate sensitivity reconstructions through, for example, North Atlantic Heinrich events or the Younger Dryas may yield unstable results, with potential anomalies to high values. Yet it may be instructive to carefully reconstruct time-series of palaeo-climate sensitivity in high temporal resolutions, to see if such transient anomalies are actually found and when/how they settle toward equilibrium values. Accurate reconstruction of global mean temperature changes will be vital to such assessments, since a large component of the temperature swings through such events may concern energy redistribution around the globe (Stocker 1998), rather than global mean change. If/when transient behaviour of palaeoclimate sensitivity could be thus established, then this might uncover interesting clues about the critical realworld processes involved, and their timescales.

Finally, palaeoclimate studies can only measure the full temperature response, which includes the delayed ocean responses $\delta_{[\mathrm{SO}]}$ and (part or all of) $\delta_{\text {[DO] }}$. For a sound like-with-like comparison, a truly equilibrated actuo-scenario should therefore include these as well. We saw already that inclusion of $\delta_{[\mathrm{SO}]}$ brings a conflict with potential contributions of $\Delta R_{[\mathrm{CFB}]}$ in the actuo-scenario (Figure 3). In time-series-based palaeoclimate studies, individual carbon-cycle components cannot be distinguished, so the best comparison between $S^{a}$ from actuo-studies and palaeo- $S_{[s f]}$ estimates would require exclusion of any $\Delta R_{[\mathrm{CFB}]}$ influences (and/or similar carbon-cycle changes; see section 3.1) from the $S^{a}$ estimate. The situation is worse with respect to the slow $\delta_{[\mathrm{DO}]}$. Including this in an $S^{a}$ estimate from actuo-studies would require consideration over thousands of years, by which time carbonate compensation, continental land-ice influences, and longterm vegetation adjustments would have become important players in the temperature developments as well (Figure 3). Also, inclusion of $\delta_{[\text {[Do] }}$ would increase the timescale of evaluation to a few thousand years, rather than a century or two into the future, which reduces the apparent relevance to society. For pragmatic reasons, $S^{a}$ is defined to include $\Delta R_{[\mathrm{T} 2]}, \Delta R_{[\mathrm{SSI}]}, \Delta R_{[\mathrm{AE}]}$, and $\delta_{[\mathrm{SO}]}$, and it is inevitable that this imposes some limitations to precise comparability with palaeoclimate-based $S_{[s f]}$ estimates.

\subsection{Dependence of palaeoclimate sensitivity on feedback efficacy changes}

Efficacies of the various processes (in essence, their contributing amplitudes) are reasonably understood for the present day, where there are many observations to constrain the inferred ranges of variation. But, as we transition into a much warmer world, the potential for efficacy changes in key feedbacks cannot be excluded and must be considered. For example, the efficacy of the snow and ice albedos may change as latitudinal distributions of snow and ice change, affecting the amount of (latitude-dependent) insolation reflection per unit area, while efficacies of the fast water-vapour and cloud feedbacks may also change with 
background temperature (e.g., von der Heydt et al 2014, 2016, Köhler et al 2015). The uncertainty ranges allowed in the actuo-scenario yield wide tails in the climate sensitivity distributions, especially at the high end (Figures 3 and 4). A possible approach to constrain the width of the tails would be by performing large ensembles of runs over wide parameter spaces with a more representative climate model over the historical period, excluding runs that do not agree with historical time-series of climate data, and then determining climate sensitivity from the remaining runs.

As is, our simple actuo-scenario's estimates for $S^{a}$ are reached after about 200 years, and range over a $95 \%$ probability envelope of 0.8 to $1.6 \mathrm{~K} /\left(\mathrm{Wm}^{-2}\right)$ around a median value of $1.1 \mathrm{~K} /\left(\mathrm{Wm}^{-2}\right)$ for the case that doesn't explicitly account for $\Delta R_{\text {[CFB] }}$, and 0.7 to $1.4 \mathrm{~K} /\left(\mathrm{Wm}^{-2}\right)$ around a median of $1.0 \mathrm{~K} /\left(\mathrm{Wm}^{-2}\right)$ for the case that does explicitly account for $\Delta R_{[\text {[CFB]. }}$ The "equilibrium" value therefore is about 1.5 times the scenario's "transient" climate sensitivity value before $\delta_{\text {[so] }}$ involvement, which has a $95 \%$ range of 0.5 to $0.9 \mathrm{~K} /\left(\mathrm{Wm}^{-2}\right)$ around a median of $0.7 \mathrm{~K} /\left(\mathrm{Wm}^{-2}\right)$ (blue bar in Figure 3a,c).

Our actuo-scenario's peak values, which mark the time when slow feedbacks have also made their maximum contribution ( $S^{\max }$ ), have a $95 \%$ probability range of 1.0 to $2.3 \mathrm{~K} /\left(\mathrm{Wm}^{-2}\right)$ around a median value of $1.5 \mathrm{~K} /\left(\mathrm{Wm}^{-2}\right)$ for the case that doesn't explicitly account for $\Delta R_{[\mathrm{CFB}]}$, and 1.0 to $2.1 \mathrm{~K} /\left(\mathrm{Wm}^{-2}\right)$ around a median of $1.4 \mathrm{~K} /\left(\mathrm{Wm}^{-2}\right)$ for the case that does explicitly account for $\Delta R_{\text {[CFB] }}$. These values are achieved after about 1000 years, and indicate a level of about $2 \times$ the scenario's "transient" climate sensitivity value.

For the palaeo-scenario, efficacies are notably less constrained, and may depend considerably on the background climate state (Köhler et al 2015, Friedrich et al 2016 , von der Heydt et al 2016). Our scenarios, using either $S_{[\mathrm{GHG}, \mathrm{LI}, \mathrm{VG}]}$ or $S_{[\mathrm{GHG}, \mathrm{LI}]}$, include the cumulative impacts of efficacy variations in all feedbacks over $\pm 50 \%$ ranges (uniformly distributed) (Figures $5 \mathrm{c}$ and 6 ). For $S_{[\mathrm{GHG}, \mathrm{LL}, \mathrm{VG}]}$, we find an "equilibrium" 95\% probability range of 0.4 to $1.3 \mathrm{~K} /\left(\mathrm{Wm}^{-2}\right)$ around a median of $0.8 \mathrm{~K} /\left(\mathrm{Wm}^{-2}\right)$. For the more common approximation in palaeo-studies, $S_{\text {[GHG,LI], }}$ we find an "equilibrium" $95 \%$ probability range of 0.5 to $1.6 \mathrm{~K} /\left(\mathrm{Wm}^{-2}\right)$ around a median of $0.9 \mathrm{~K} /\left(\mathrm{Wm}^{-2}\right)$ (Figures $5 \mathrm{c}$ and 6$)$. The latter estimate is the most useful one for comparison with published equilibrium palaeoclimate sensitivity estimates, since those typically were not corrected for $\Delta R_{[\mathrm{VG}]}$ either.

With total 95\% bounds of 0.4-1.6 K/(Wm-2), our assessments for $S_{[\mathrm{GHG}, \mathrm{LI}]}$ and $S_{[\mathrm{GHG}, \mathrm{LI}, \mathrm{VG}]}$ closely approximate the $95 \%$ bounds of $0.3-1.9 \mathrm{~K} /\left(\mathrm{Wm}^{-2}\right)$ for similarly defined, observation-based estimates for the last 65 million years (PALAEOSENS 2012) (Figure 6). We infer, in agreement with Köhler et al (2015), that the wide range of PALAEOSENS (2012) likely results from integration of observations across a range of state-dependent palaeo-climate sensitivity values through time. This is an important point: it would seem that the width of previously reconstructed palaeo-climate sensitivity distributions is not so much a function of random (proxy-based) measurement uncertainties, but instead is primarily driven by integration of numerous, hitherto unrecognised, narrower statedependent distributions. Given that the width of our simple scenario's range 
agrees well with that found from observations, we tentatively infer that overall efficacy changes through time likely remained within roughly $\pm 50 \%$.

Finally, we compare results between Figures 4 and 6. At 0.7-1.6 K/(Wm-2) around a median of 1.0 to $1.1 \mathrm{~K} /\left(\mathrm{Wm}^{-2}\right), S^{a}$ from our actuo-scenario appears slightly higher than $S_{[s f]}$ from the palaeo-scenario, at $0.4-1.6 \mathrm{~K} /\left(\mathrm{Wm}^{-2}\right)$ around a median of 0.8 to $0.9 \mathrm{~K} /\left(\mathrm{Wm}^{-2}\right)$. However, this slight offset likely results from differences in the way the calculations have been constrained between the scenarios. With respect to the distribution width difference, we see potential for palaeo-studies to provide $S_{[s]}$ distributions that portray real total climate-system responses that represent real-world realisations of climate change, and for careful work (especially with respect to chronological relationships between time-series of data) to eventually deconvolve the overall probability distributions into narrower ones that account for climate-state dependence. Thus, palaeodata studies may provide key templates ("prior" distributions) for exercises to select best-matching subsets from model mega-ensemble assessments of future climate developments.

Finally, we consider the question of how to tease out state dependence from palaeodata using very carefully designed experiments (Figure 5). It cannot be excluded that this will be possible, but the apparent size of the $95 \%$ probability envelope to individual scenarios suggests that estimates for different climate states are likely to overlap, except in extremely contrasting cases.

\subsection{Comparison with other approaches}

While the above conceptual framework is different in its focus on the timedomain, it follows the general principles laid out before in PALAEOSENS (2012) and further explored in Royer (2016). Yet the framework's focus on radiative forcing anomalies to calculate temperature change and climate sensitivity may be less familiar to climate modellers. Therefore, we here assess the implications of a focus on the time-domain in a framework of feedback analysis.

Classically, a perturbation of the radiative forcing $\Delta R_{F}$, for example by an instantaneous doubling of atmospheric $\mathrm{CO}_{2}$ concentrations, leads to a temperature anomaly $\Delta T(t)=-\Delta R_{F} / \Sigma \lambda_{i}(t)$, where the sum of feedback parameters consists of the Planck feedback $\left(\lambda_{P}=-3.2 \mathrm{Wm}^{-2} \mathrm{~K}^{-1}\right)$ responsible for a rise in the outgoing long-wave radiation (OLW), the sum of all other fast feedbacks $\left(\lambda_{\text {other-ff, }}\right.$, for surface albedo, water vapour, lapse rate, and clouds) and contributions from ocean heat uptake efficiency $(\kappa)$ to the surface and deep ocean. The latter are in the classical framework (Dufresne \& Bony 2008) not called feedbacks, but still can be calculated as such. In our example demonstration of how this framework works (Figure 7), these feedbacks are parameterised based on multi-model results from CMIP3 (Dufresne \& Bony 2008). Although newer (CMIP5) results have been published (Vial et al 2013), these include forcing adjustment, which we prefer to ignore here because it complicates the system and might be negligible in the palaeo-framework.

We thus end up with a time-dependent term for $\lambda_{\text {other-ff }}=+1.9 \mathrm{Wm}^{-2} \mathrm{~K}^{-1}$, which is modulated with signal-development similar as given in Equation (2) to obtain 
full amplitude with $\tau=10$ years. The pure Planck feedback then leads to a temperature rise of about $1 \mathrm{~K}$ after the initial year and together with theses fast feedbacks to about $2 \mathrm{~K}$ after a decade, in agreement with recent estimates of the transient climate sensitivity (Storelvmo et al 2016). Adding the ocean heat uptake efficiency to the surface ocean $\left(\kappa_{1}\right.$ or $\lambda_{S O}=-0.67 \mathrm{Wm}^{-2} \mathrm{~K}^{-1}$ with $\tau=100$ years) then leads to a temperature rise of $3 \mathrm{~K}$ after a century, and to a rise in the time-dependent specific climate sensitivity $S(t)=\Delta T / \Delta R_{F}$ from $0.52 \mathrm{~K} /\left(\mathrm{Wm}^{-2}\right)$ after a decade to $0.79 \mathrm{~K} /\left(\mathrm{Wm}^{-2}\right)$ after a century, in agreement with the estimate of ECS in CMIP3. Taken furthermore into account that model simulations underlying the classical calculations of ECS are not in full equilibrium (Gregory et al 2004, Hansen et al 2011, Bloch-Johnson et al 2015, Rugenstein et al 2016), one might define deep ocean heat uptake efficiency as another feedback parameter ( $\kappa_{2}$ or $\lambda_{D O}=0.5 \mathrm{Wm}^{-2} \mathrm{~K}^{-1}$ with $\tau=2000$ year) that leads to a further temperature rise to a $\Delta T$ of up to $5 \mathrm{~K}$ on a multi-millennial timescale.

Similar to this $2 \mathrm{xCO}_{2}$ example, one might translate the radiative forcing anomalies for our actuo- and palaeo-scenarios (as summarised in Tables 1 and 2) into a framework of feedback analysis. This would yield figures similar to Figure 7 , but no new insights with respect to the time-dependence of $S$, and therefore is not further evaluated here.

\section{Summary points and future issues}

We analyse and compare approaches for determining climate sensitivity in studies of modern/future ("actuo") and past ("palaeo") climate, using graphical illustrations based on highly idealised scenarios. This reveals problems with determining a unique value for equilibrium climate sensitivity in both actuo and palaeo scenarios, since the processes involved are not strictly separated in time, and/or are insufficiently understood for a sound quantification. In addition, there are issues with understanding the efficacies of the dominant processes (particularly for the palaeo), which likely underpin state dependence of climate sensitivity and the length of the "tails" of reconstructed climate sensitivity probability density functions. The analysis presented here suggests that the width of previously reconstructed palaeo-climate sensitivity distributions likely reflects the integration of numerous state-dependent distributions.

We identify several key requirements for advancing the debate. These are: (1) that precise chronological control is needed when comparing different proxy records of global temperature changes and forcings/feedbacks; (2) that new approaches/strategies to reconstruct mean global temperature changes from palaeostudies are needed, given that even reconstructions through the LGM disagree over a wide range; (3) that model-independent ways of evaluating the records are needed, to avoid introducing model-dependent artefacts in the calculated climate sensitivities (i.e., circular reasoning). Further, we find continued need for: (4) refined understanding of how certain parameters (e.g., mean global temperature, or $\mathrm{CO}_{2}$ concentrations) are estimated with different proxies (method inter-comparison studies); (5) detailed description of assumptions and uncertainties, and transparent and complete propagation of these into the calculated sensitivity distributions; (6) careful and transparent 
960

961

962

963

964

965

966

967

968

969

970

971

972

973

974

975

976

977

978

979

980

981

982

983

984

985

986

987

988

989

990

991

992

993

994

995

996

997

998

999

1000

1001

1002

1003

1004

definition of which terms exactly are being compared between case studies; and (7) elaboration of high-quality records for the major missing slow feedback (vegetation).

Finally, we infer that the main focus in current work concerns potential climate background-state dependence of climate sensitivity. Our analysis suggests that it will be challenging to statistically robustly confirm this using palaeodata. No doubt this problem will continue to receive a lot of attention within the next few years - hopefully innovative approaches will be developed to constrain this critical aspect. In our view, a better understanding of feedback efficacy changes through time will be critical to reducing uncertainties sufficiently for statistical distinction of state-dependence in climate sensitivity.

Acknowledgements. E.J.R. and G.M. acknowledge support by the Australian Research Council, via Australian Laureate Fellowship FL120100050. A.H. acknowledges support by the program of the Netherlands Earth System Science Centre (NESSC), financially supported by the Ministry of Education, Culture and Science (OCW). P.K. is funded by PACES-II, the Helmholtz research programme to which the Alfred Wegener Institut contributes.

\section{LITERATURE CITED}

Abe-Ouchi A, Saito F, Kawamura K, Raymo ME, Okuno Ji, et al. 2013. Insolationdriven 100,000-year glacial cycles and hysteresis of ice-sheet volume. Nature 500: 190-93

Anagnostou E, John EH, Edgar KM, Foster GL, Ridgwell A, et al. 2016. Changing atmospheric $\mathrm{CO}_{2}$ concentration was the primary driver of early Cenozoic climate. Nature 533: 380-84

Annan JD, Hargreaves JC. 2013. A new global reconstruction of temperature changes at the Last Glacial Maximum. Clim. Past. 9: 367-76

Arrhenius S. 1896. On the influence of carbonic acid in the air upon the temperature of the ground. Philosophical Magazine Series 5 41: 237-76

Billups K. 2015. CLIMATE SCIENCE Timing is everything during deglaciations. Nature 522: 163-64

Bloch-Johnson J, Pierrehumbert RT, Abbot DS. 2015. Feedback temperature dependence determines the risk of high warming. Geophys. Res. Lett. 42: 4973-80

Bony S, Colman R, Kattsov VM, Allan RP, Bretherton CS, et al. 2006. How well do we understand and evaluate climate change feedback processes? Journal of Climate 19: 3445-82

Bony S, Stevens B, Frierson DMW, Jakob C, Kageyama M, et al. 2015. Clouds, circulation and climate sensitivity. Nature Geoscience 8: 261-68

Byrne B, Goldblatt C. 2014. Radiative forcing at high concentrations of wellmixed greenhouse gases. Geophys. Res. Lett. 41: 152-60

Callendar GS. 1938. The artificial production of carbon dioxide and its influence on temperature. Quarterly Journal of the Royal Meteorological Society 64: $223-40$ 
1005

1006

1007

1008

1009

1010

1011

1012

1013

1014

1015

1016

1017

1018

1019

1020

1021

1022

1023

1024

1025

1026

1027

1028

1029

1030

1031

1032

1033

1034

1035

1036

1037

1038

1039

1040

1041

1042

1043

1044

1045

1046

1047

1048

1049

1050

1051
Charney JG, Arakawa A, Baker DJ, Bolin B, Dickinson RE, et al. 1979. Carbon dioxide and climate: a scientific assessment. National Academy of Sciences, Washington, DC.

Cheng H, Edwards RL, Sinha A, Spotl C, Yi L, et al. 2016. The Asian monsoon over the past 640,000 years and ice age terminations. Nature 534: 640-46

Clark PU, Shakun JD, Marcott SA, Mix AC, Eby M, et al. 2016. Consequences of twenty-first-century policy for multi-millennial climate and sea-level change. Nature Climate Change 6: 360-69

Crowley TJ. 1990. Are there any satisfactory geologic analogs for a future greenhouse warming? Journal of Climate 3: 1282-92

Crucifix M. 2006. Does the Last Glacial Maximum constrain climate sensitivity? Geophys. Res. Lett. 33

DeConto RM, Pollard D. 2016. Contribution of Antarctica to past and future sealevel rise. Nature 531: 591-97

Denton GH, Anderson RF, Toggweiler JR, Edwards RL, Schaefer JM, Putnam AE. 2010. The Last Glacial Termination. Science 328: 1652-56

Drijfhout S, Bathiany S, Beaulieu C, Brovkin V, Claussen M, et al. 2015. Catalogue of abrupt shifts in Intergovernmental Panel on Climate Change climate models. Proceedings of the National Academy of Sciences 112: E5777-E86

Dufresne JL, Bony S. 2008. An assessment of the primary sources of spread of global warming estimates from coupled atmosphere-ocean models. Journal of Climate 21: 5135-44

Etminan M, Myhre G, Highwood EJ, Shine KP. 2016. Radiative forcing of carbon dioxide, methane, and nitrous oxide: A significant revision of the methane radiative forcing. Geophys. Res. Lett. 43: 12614-23

Fasullo JT, Trenberth KE. 2012. A Less Cloudy Future: The Role of Subtropical Subsidence in Climate Sensitivity. Science 338: 792-94

Forster PM. 2016. Inference of Climate Sensitivity from Analysis of Earth's Energy Budget In Annual Review of Earth and Planetary Sciences, Vol 44, ed. R Jeanloz, KH Freeman, pp. 85-106

Foster GL, Rohling EJ. 2013. Relationship between sea level and climate forcing by $\mathrm{CO}_{2}$ on geological timescales. Proceedings of the National Academy of Sciences of the United States of America 110: 1209-14

Friedrich T, Timmermann A, Tigchelaar M, Timm OE, Ganopolski A. 2016. Nonlinear climate sensitivity and its implications for future greenhouse warming. Science Advances 2

Gasson E, DeConto RM, Pollard D. 2016. Modeling the oxygen isotope composition of the Antarctic ice sheet and its significance to Pliocene sea level. Geology 44: 827-30

Gleckler PJ, Durack PJ, Stouffer RJ, Johnson GC, Forest CE. 2016. Industrial-era global ocean heat uptake doubles in recent decades. Nature Climate Change 6: 394-+

Grant KM, Rohling EJ, Bar-Matthews M, Ayalon A, Medina-Elizalde M, et al. 2012. Rapid coupling between ice volume and polar temperature over the past 150,000 years. Nature 491: 744-47

Grant KM, Rohling EJ, Ramsey CB, Cheng H, Edwards RL, et al. 2014. Sea-level variability over five glacial cycles. Nature communications 5 
1052

1053

1054

1055

1056

1057

1058

1059

1060

1061

1062

1063

1064

1065

1066

1067

1068

1069

1070

1071

1072

1073

1074

1075

1076

1077

1078

1079

1080

1081

1082

1083

1084

1085

1086

1087

1088

1089

1090

1091

1092

1093

1094

1095

1096

1097

1098

Gregory JM, Ingram WJ, Palmer MA, Jones GS, Stott PA, et al. 2004. A new method for diagnosing radiative forcing and climate sensitivity. Geophys. Res. Lett. 31

Hansen J, Kharecha P, Sato M, Masson-Delmotte V, Ackerman F, et al. 2013a. Assessing "Dangerous Climate Change": Required Reduction of Carbon Emissions to Protect Young People, Future Generations and Nature. Plos One 8

Hansen J, Lacis A, Rind D, Russell G, Stone P, et al. 1984. Climate sensitivity: Analysis of feedback mechanisms In Climate processes and climate sensitivity, pp. 130-63: American Geophysical Union

Hansen J, Ruedy R, Sato M, Lo K. 2010. Global surface temperature change. Reviews of Geophysics 48

Hansen J, Sato M, Kharecha P, Beerling D, Berner R, et al. 2008. Target Atmospheric $\mathrm{CO}_{2}$ : Where Should Humanity Aim? The Open Atmospheric Science Journal 2: 217-31

Hansen J, Sato M, Kharecha P, Russell G, Lea DW, Siddall M. 2007. Climate change and trace gases. Philosophical Transactions of the Royal Society aMathematical Physical and Engineering Sciences 365: 1925-54

Hansen J, Sato M, Kharecha P, von Schuckmann K. 2011. Earth's energy imbalance and implications. Atmospheric Chemistry and Physics 11: 13421-49

Hansen J, Sato M, Kharecha P, von Schuckmann K, Beerling DJ, et al. 2016. Young People's Burden: Requirement of Negative CO2 Emissions. Earth Syst. Dynam. Discuss. 2016: 1-40

Hansen J, Sato M, Ruedy R, Nazarenko L, Lacis A, et al. 2005. Efficacy of climate forcings. Journal of Geophysical Research-Atmospheres 110

Hansen J, Sato M, Russell G, Kharecha P. 2013b. Climate sensitivity, sea level and atmospheric carbon dioxide. Philosophical Transactions of the Royal Society a-Mathematical Physical and Engineering Sciences 371

Hansen JE, Sato M. 2012. Paleoclimate Implications for Human-Made Climate Change In Climate Change: Inferences from Paleoclimate and Regional Aspects, ed. A Berger, F Mesinger, D Sijacki, pp. 21-47. Vienna: Springer Vienna

Hays JD, Imbrie J, Shackleton NJ. 1976. Variations in earths orbit: pacemaker of ice ages. Science 194: 1121-32

Hegerl GC, Crowley TJ, Hyde WT, Frame DJ. 2006. Climate sensitivity constrained by temperature reconstructions over the past seven centuries. Nature 440: $1029-32$

Hoffman JS, Clark PU, Parnell AC, He F. 2017. Regional and global sea-surface temperatures during the last interglaciation. Science 355: 276-79

Holloway MD, Sime LC, Singarayer JS, Tindall JC, Bunch P, Valdes PJ. 2016. Antarctic last interglacial isotope peak in response to sea ice retreat not ice-sheet collapse. Nature Communications 7

IPCC. 2013. Climate Change 2013: The Physical Science Basis. Contribution of Working Group I to the Fifth Assessment Report of the Intergovernmental Panel on Climate Change. Cambridge, United Kingdom and New York, NY, USA: Cambridge University Press. 1535 pp. 
1099

1100

1101

1102

1103

1104

1105

1106

1107

1108

1109

1110

1111

1112

1113

1114

1115

1116

1117

1118

1119

1120

1121

1122

1123

1124

1125

1126

1127

1128

1129

1130

1131

1132

1133

1134

1135

1136

1137

1138

1139

1140

1141

1142

1143

1144

1145

1146
Kemp DB, Eichenseer K, Kiessling W. 2015. Maximum rates of climate change are systematically underestimated in the geological record. Nature Communications 6

Kirschvink JL. 1992. Late Proterozoic Low Latitude Global Glaciation: The Snowball Earth In The Proterozoic biosphere: a multidisciplinary study, ed. JW Schoff, C Klein, pp. 51-52. New York: Cambridge University Press

Knutti R, Hegerl GC. 2008. The equilibrium sensitivity of the Earth's temperature to radiation changes. Nature Geoscience 1: 735-43

Knutti R, Rugenstein MAA. 2015. Feedbacks, climate sensitivity and the limits of linear models. Philosophical Transactions of the Royal Society of London A: Mathematical, Physical and Engineering Sciences 373

Köhler P, Bintanja R, Fischer H, Joos F, Knutti R, et al. 2010. What caused Earth's temperature variations during the last 800,000 years? Data-based evidence on radiative forcing and constraints on climate sensitivity. Quat. Sci. Rev. 29: 129-45

Köhler P, de Boer B, von der Heydt AS, Stap LB, van de Wal R. 2015. On the state dependency of the equilibrium climate sensitivity during the last 5 million years. Clim. Past. 11: 1801-23

Lambeck K, Rouby H, Purcell A, Sun Y, Sambridge M. 2014. Sea level and global ice volumes from the Last Glacial Maximum to the Holocene. Proceedings of the National Academy of Sciences of the United States of America 111: 15296-303

Lord NS, Ridgwell A, Thorne MC, Lunt DJ. 2016. An impulse response function for the "long tail" of excess atmospheric CO2 in an Earth system model. Global Biogeochemical Cycles 30: 2-17

Lunt DJ, Haywood AM, Schmidt GA, Salzmann U, Valdes PJ, Dowsett HJ. 2010. Earth system sensitivity inferred from Pliocene modelling and data. Nature Geoscience 3: 60-64

Mann ME. 2014. False Hope. Scientific American 310: 78-81

Marcott SA, Bauska TK, Buizert C, Steig EJ, Rosen JL, et al. 2014. Centennial-scale changes in the global carbon cycle during the last deglaciation. Nature 514: 616-+

Margo. 2009. Constraints on the magnitude and patterns of ocean cooling at the Last Glacial Maximum. Nature Geoscience 2: 127-32

Marino G, Rohling EJ, Rodriguez-Sanz L, Grant KM, Heslop D, et al. 2015. Bipolar seesaw control on last interglacial sea level. Nature 522: 197-201

Martinez-Boti MA, Foster GL, Chalk TB, Rohling EJ, Sexton PF, et al. 2015. PlioPleistocene climate sensitivity evaluated using high-resolution $\mathrm{CO}_{2}$ records. Nature 518: 49-54

Marvel K, Schmidt GA, Miller RL, Nazarenko LS. 2016. Implications for climate sensitivity from the response to individual forcings. Nature Climate Change 6: 386-89

Masson-Delmotte V, Buiron D, Ekaykin A, Frezzotti M, Gallee H, et al. 2011. A comparison of the present and last interglacial periods in six Antarctic ice cores. Clim. Past. 7: 397-423

Masson-Delmotte V, Stenni B, Pol K, Braconnot P, Cattani O, et al. 2010. EPICA Dome C record of glacial and interglacial intensities. Quat. Sci. Rev. 29: 113-28 
Myhre G, Highwood EJ, Shine KP, Stordal F. 1998. New estimates of radiative forcing due to well mixed greenhouse gases. Geophys. Res. Lett. 25: 271518

Myhre G, Shindell D, Bréon F-M, Collins W, Fuglestvedt J, et al. 2013. Anthropogenic and Natural Radiative Forcing In Climate Change 2013: The Physical Science Basis. Contribution of Working Group I to the Fifth Assessment Report of the Intergovernmental Panel on Climate Change, ed. TF Stocker, D Qin, G-K Plattner, M Tignor, SK Allen, et al, pp. 659-740. Cambridge, United Kingdom and New York, NY, USA: Cambridge University Press

Pagani M, Liu ZH, LaRiviere J, Ravelo AC. 2010. High Earth-system climate sensitivity determined from Pliocene carbon dioxide concentrations. Nature Geoscience 3: 27-30

PALAEOSENS. 2012. Making sense of palaeoclimate sensitivity. Nature 491: 68391

Poulsen CJ, Jacob RL, Pierrehumbert RT, Huynh TT. 2002. Testing paleogeographic controls on a Neoproterozoic snowball Earth. Geophys. Res. Lett. 29

Rohling EJ, Grant K, Bolshaw M, Roberts AP, Siddall M, et al. 2009. Antarctic temperature and global sea level closely coupled over the past five glacial cycles. Nature Geoscience 2: 500-04

Rohling EJ, Haigh ID, Foster GL, Roberts AP, Grant KM. 2013. A geological perspective on potential future sea-level rise. Scientific reports 3

Rohling EJ, Medina-Elizalde M, Shepherd JG, Siddall M, Stanford JD. 2012. Sea Surface and High-Latitude Temperature Sensitivity to Radiative Forcing of Climate over Several Glacial Cycles. Journal of Climate 25: 1635-56

Royer DL. 2016. Climate Sensitivity in the Geologic Past In Annual Review of Earth and Planetary Sciences, Vol 44, ed. R Jeanloz, KH Freeman, pp. 27793

Rugenstein MAA, Gregory JM, Schaller N, Sedlacek J, Knutti R. 2016. Multiannual Ocean-Atmosphere Adjustments to Radiative Forcing. Journal of Climate 29: 5643-59

Schmittner A, Urban NM, Shakun JD, Mahowald NM, Clark PU, et al. 2011. Climate Sensitivity Estimated from Temperature Reconstructions of the Last Glacial Maximum. Science 334: 1385-88

Schneider von Deimling T, Held H, Ganopolski A, Rahmstorf S. 2006. Climate sensitivity estimated from ensemble simulations of glacial climate. Clim. Dyn. 27: 149-63

Shackleton NJ. 2000. The 100,000-year ice-age cycle identified and found to lag temperature, carbon dioxide, and orbital eccentricity. Science 289: 1897902

Shakun JD, Clark PU, He F, Marcott SA, Mix AC, et al. 2012. Global warming preceded by increasing carbon dioxide concentrations during the last deglaciation. Nature 484: 49-54

Sherwood SC, Bony S, Dufresne JL. 2014. Spread in model climate sensitivity traced to atmospheric convective mixing. Nature 505: 37-42

Skinner L. 2012. A Long View on Climate Sensitivity. Science 337: 917-19

Snyder CW. 2016. Evolution of global temperature over the past two million years. Nature 538: 226-28 
1196

1197

1198

1199

1200

1201

1202

1203

1204

1205

1206

1207

1208

1209

1210

1211

1212

1213

1214

1215

1216

1217

1218

1219

1220

1221

1222

1223

1224

1225

1226

1227

1228

1229

1230

1231

1232

1233

1234

1235

1236

1237

1238

1239

1240

1241

1242
Stevens B, Sherwood SC, Bony S, Webb MJ. 2016. Prospects for narrowing bounds on Earth's equilibrium climate sensitivity. Earths Future 4: 512-22

Stocker TF. 1998. The seesaw effect. Science 282: 61-62

Stocker TF, Johnsen SJ. 2003. A minimum thermodynamic model for the bipolar seesaw. Paleoceanography 18

Storelvmo T, Leirvik T, Lohmann U, Phillips PCB, Wild M. 2016. Disentangling greenhouse warming and aerosol cooling to reveal Earth's climate sensitivity. Nature Geoscience 9: 286-+

Tzedakis PC, Crucifix M, Mitsui T, Wolff EW. 2017. A simple rule to determine which insolation cycles lead to interglacials. Nature 542: 427-32

van de Wal RSW, de Boer B, Lourens LJ, Köhler P, Bintanja R. 2011. Reconstruction of a continuous high-resolution $\mathrm{CO}_{2}$ record over the past 20 million years. Clim. Past. 7: 1459-69

Vial J, Dufresne JL, Bony S. 2013. On the interpretation of inter-model spread in CMIP5 climate sensitivity estimates. Clim. Dyn. 41: 3339-62

von der Heydt AS, Ashwin P. 2016. State dependence of climate sensitivity: attractor constraints and palaeoclimate regimes. Dynamics and Statistics of the Climate System 1: dzx001-dzx01

von der Heydt AS, Dijkstra HA, van de Wal RSW, Caballero R, Crucifix M, et al. 2016. Lessons on Climate Sensitivity From Past Climate Changes. Current Climate Change Reports 2: 148-58

von der Heydt AS, Köhler P, van de Wal RSW, Dijkstra HA. 2014. On the state dependency of fast feedback processes in (paleo) climate sensitivity. Geophys. Res. Lett. 41: 6484-92

Whitmarsh, F., Zika, J., Czaja, A. 2015. Ocean heat uptake and the global surface temperature record. Grantham Institute Briefing paper No 14. September 2015. https://www.imperial.ac.uk/media/imperial-college/granthaminstitute/public/publications/briefing-papers/Ocean-heat-uptake--Grantham-BP-15.pdf

Zachos JC, Schouten S, Bohaty S, Quattlebaum T, Sluijs A, et al. 2006. Extreme warming of mid-latitude coastal ocean during the Paleocene-Eocene Thermal Maximum: Inferences from TEX86 and isotope data. Geology 34: 737-40

Zeebe RE. 2013. Time-dependent climate sensitivity and the legacy of anthropogenic greenhouse gas emissions. Proceedings of the National Academy of Sciences of the United States of America 110: 13739-44

Zeebe RE, Ridgwell A, Zachos JC. 2016. Anthropogenic carbon release rate unprecedented during the past 66 million years. Nature Geoscience 9: 325-29

Zeebe RE, Zachos JC, Dickens GR. 2009. Carbon dioxide forcing alone insufficient to explain Palaeocene-Eocene Thermal Maximum warming. Nature Geoscience 2: 576-80

Zhou C, Zelinka MD, Klein SA. 2016. Impact of decadal cloud variations on the Earth's energy budget. Nature Geoscience 9: 871-74 
Table 1. Parameter values used in the idealised actuo-climate sensitivity scenario.

\begin{tabular}{|c|c|c|c|c|c|}
\hline Description & Code & $\begin{array}{l}\text { Estimated } \\
\text { duration for } \\
\text { full response } \\
(\tau, \text { in } y)^{b} \\
\end{array}$ & $\begin{array}{l}\text { Full range } \\
\text { ( } \varepsilon_{\tau} ; \text { uniform } \\
\text { distribution) }\end{array}$ & $\begin{array}{l}\text { Full amplitude }(h, \text { in } \\
\left.\mathrm{Wm}^{-2}\right)^{\mathrm{a}}\end{array}$ & $\begin{array}{l}\text { Full range } \\
\left(\varepsilon_{h} ; \text { uniform }\right. \\
\text { distribution) } \\
(y) \\
\end{array}$ \\
\hline $\begin{array}{l}\text { Direct responses, } \\
\text { incl. vapour and } \\
\text { cloud feedbacks }\end{array}$ & $\Delta R_{[\mathrm{T} 2]}$ & 1 & $\pm 50 \%$ & 2.2 & $\pm 10 \%$ \\
\hline $\begin{array}{l}\text { Aerosol \& land- } \\
\text { surface feedbacks }\end{array}$ & $\Delta R_{[\mathrm{AE}]}$ & 10 & $\pm 50 \%$ & -1.2 & $\pm 50 \%$ \\
\hline $\begin{array}{l}\text { Snow \& sea-ice } \\
\text { albedo feedback }\end{array}$ & $\Delta R_{[\mathrm{SSI}]}$ & 20 & $\pm 50 \%$ & 0.4 & $\pm 10 \%$ \\
\hline $\begin{array}{l}\text { Carbon cycle } \\
\text { feedbacks }\end{array}$ & $\Delta R_{[\mathrm{CFB}]}$ & 150 & $\pm 50 \%$ & $0.05 \Delta R_{[\mathrm{T} 2]}$ & $\pm 50 \%$ \\
\hline $\begin{array}{l}\text { Surface ocean } \\
\text { temperature } \\
\text { equilibration }\end{array}$ & $\delta_{[\mathrm{so}]}$ & 150 & $\pm 50 \%$ & 0.55 & $\pm 10 \%$ \\
\hline $\begin{array}{l}\text { Continental ice } \\
\text { albedo feedback }\end{array}$ & $\Delta R_{[\mathrm{LI}]}$ & 750 & $\pm 50 \%$ & $3(10 / 125)$ & $\pm 50 \%$ \\
\hline $\begin{array}{l}\text { Deep ocean } \\
\text { temperature } \\
\text { equilibration }\end{array}$ & $\delta_{[\mathrm{DO}]}$ & 1500 & $\pm 50 \%$ & 0.55 & $\pm 10 \%$ \\
\hline Vegetation albedo & $\Delta R_{[\mathrm{VG}]}$ & 500 & $\pm 50 \%$ & $0.05\left(\Delta R_{[\mathrm{AE}]}+\Delta R_{[\mathrm{T} 2]}\right)$ & $\pm 50 \%$ \\
\hline $\begin{array}{l}\text { Carbonate } \\
\text { compensation }\end{array}$ & $\Delta R_{[\mathrm{CC}]}$ & 10,000 & $\pm 50 \%$ & $-0.5\left(\Delta R_{[\mathrm{CFB}]}+0.5 \Delta R_{[\mathrm{T} 2]}\right)$ & $\pm 50 \%$ \\
\hline Weathering & $\Delta R_{[\mathrm{WE}]}$ & 200,000 & $\pm 50 \%$ & $-0.5\left(\Delta R_{[\mathrm{CFB}]}+0.5 \Delta R_{[\mathrm{T} 2]}\right)$ & $\pm 50 \%$ \\
\hline
\end{tabular}

a Values are set in relation to a total effective greenhouse-gas radiative forcing of $3.7 \mathrm{Wm}^{-2}$ with associated negative aerosol and land-surface feedback of $-1.2 \mathrm{Wm}^{-2}$ (Figure 2, and explanation in main text section 3.1). Argumentation for the most important amplitude settings was given in the main text. In addition, the impacts of carbonate compensation and weathering are arbitrarily set in a very simple manner to each remove the forcing and immediate feedbacks related to half of the carbon emissions.

b Values for most parameters are discussed in the text. The $10^{5}$ years timescale for weathering is after Lord et al (2016). 
Table 2. Parameter values used in the idealised palaeo-climate sensitivity scenario.

\begin{tabular}{|c|c|c|c|c|c|}
\hline Description & Code $^{a}$ & $\begin{array}{l}\text { Estimated } \\
\text { duration for } \\
\text { full response } \\
(\tau, \text { in } y) \\
\end{array}$ & $\begin{array}{l}\text { Full range } \\
\text { ( } \varepsilon_{\tau} ; \text { uniform } \\
\text { distribution) }\end{array}$ & $\begin{array}{l}\text { Full } \\
\text { amplitude }(h, \\
\text { in }\left(\mathrm{m}^{-2}\right)^{\mathrm{b}}\end{array}$ & $\begin{array}{l}\text { Full range } \\
\text { ( } \varepsilon_{h} ; \text { uniform } \\
\text { distribution) }\end{array}$ \\
\hline $\begin{array}{l}\text { Initial carbon cycle } \\
\text { (greenhouse-gas) } \\
\text { feedbacks }\end{array}$ & $\Delta R$ [GHGi $]$ & $\tau_{[\mathrm{GHG} i]}=50$ & $\pm 50 \%$ & $\varphi 2.5$ & $\pm 50 \%$ \\
\hline $\begin{array}{l}\text { Initial direct } \\
\text { responses, incl. } \\
\text { vapour and cloud } \\
\text { feedbacks }\end{array}$ & $\Delta R[\mathrm{~T} 2 \mathrm{i}]$ & $\tau_{[\mathrm{GHG} i]}+1$ & $\pm 0.5 \mathrm{y}$ & $\varphi 3$ & $\pm 50 \%$ \\
\hline $\begin{array}{l}\text { Initial snow \& sea- } \\
\text { ice albedo feedback }\end{array}$ & $\Delta R[\mathrm{SSIi}]$ & $\tau[\mathrm{GHG} i]+20$ & $\pm 10 \mathrm{y}$ & $\varphi 2$ & $\pm 50 \%$ \\
\hline $\begin{array}{l}\text { Initial aerosol \& } \\
\text { land-surface } \\
\text { feedbacks }\end{array}$ & $\Delta R[\mathrm{AEi}]$ & $\tau_{[\mathrm{GHG} i]}+10$ & $\pm 5 y$ & $\varphi 1.5$ & $\pm 50 \%$ \\
\hline $\begin{array}{l}\text { Continental ice } \\
\text { albedo feedback }\end{array}$ & $\Delta R[\mathrm{LI}]$ & $\tau_{[\mathrm{LI}]}=6000$ & $\pm 50 \%$ & 3 & $\pm 50 \%$ \\
\hline $\begin{array}{l}\text { Snow \& sea-ice } \\
\text { albedo feedback }\end{array}$ & $\Delta R$ [SSIr] & $\tau_{[\mathrm{LI}]}+20$ & $\pm 10 \mathrm{y}$ & $(1-\varphi) 2$ & $\pm 50 \%$ \\
\hline $\begin{array}{l}\text { Carbon cycle } \\
\text { (greenhouse-gas) } \\
\text { feedbacks }\end{array}$ & $\Delta R$ [GHGr] & $\tau_{[\mathrm{SSI}]}+200$ & $\pm 100 \mathrm{y}$ & $(1-\varphi) 2.5$ & $\pm 50 \%$ \\
\hline $\begin{array}{l}\text { Direct responses, } \\
\text { incl. vapour and } \\
\text { cloud feedbacks }\end{array}$ & $\Delta R[\mathrm{~T} 2 \mathrm{r}]$ & $\tau[\mathrm{GHG}]+1$ & $\pm 0.5 \mathrm{y}$ & $(1-\varphi) 3$ & $\pm 50 \%$ \\
\hline $\begin{array}{l}\text { Aerosol \& land- } \\
\text { surface feedbacks }\end{array}$ & $\Delta R[\mathrm{AEr}]$ & $\tau_{[\mathrm{LI}]}+10$ & $\pm 5 y$ & $(1-\varphi) 1.5$ & $\pm 50 \%$ \\
\hline Vegetation albedo & $\Delta R[\mathrm{VGr}]$ & $\tau_{[\mathrm{LI}]}+500$ & $\pm 250 \mathrm{y}$ & 1 & $\pm 50 \%$ \\
\hline
\end{tabular}

a Forcing amplitudes are based on a typical deglaciation within the late Pleistocene glacial cycles as discussed by (Köhler et al 2010) and Rohling et al (2012), as outlined in main text section 3.2. Our scenario apportions values to fast feedback contributions within a total $\Delta R[f f$ that is held proportional to the total of slow feedbacks contributions, $\Delta R_{[s]}$, after PALAEOSENS (2012). The radiative subdivisions used for the various fast feedbacks is irrelevant - it's used only for illustration. For $\Delta R_{[\mathrm{GHG}]}, \Delta R_{[\mathrm{T} 2]}, \Delta R_{[\mathrm{SSI}]}$, and $\Delta R_{[\mathrm{AE}]}$, we incorporate a schematic representation of an initial, rapid response to the onset of deglaciation (indicated in the code with $i$ ), and a second, remaining component (indicated in the code with $r$ ) that is delayed as it co-evolves with ice-volume reduction (see section 3.2).

$\mathrm{b}$ The proportion of the initial responses is set by factor $\varphi$, which we tentatively determined at 0.15 (see text). Changing $\varphi$ does not materially change our conclusions. Initial responses are set to start with initial carbon cycle responses within 25 to 75 years after the initial (orbital insolation) perturbation (see text). Changing this does not materially affect the conclusions. 
Figure 1. Timescales of processes involved in climate sensitivity. After PALAEOSENS (2012).

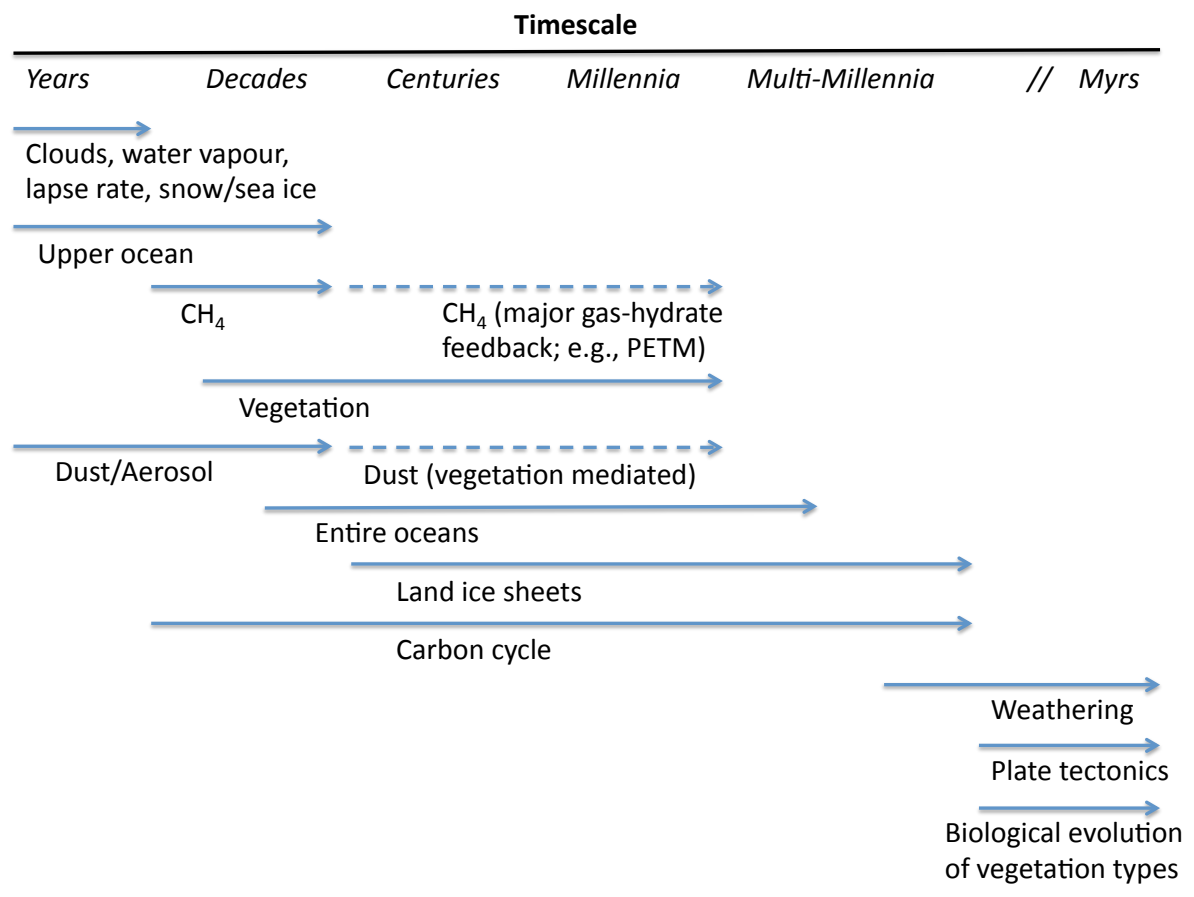

Figure 2. Estimated effective climate forcings for the "actuo"-scenario (update through 2015 of Hansen et al 2005). Forcings are based on observations of each gas, except simulated $\mathrm{CH}_{4}$-induced changes of $\mathrm{O}_{3}$ and stratospheric $\mathrm{H}_{2} \mathrm{O}$ included in the $\mathrm{CH}_{4}$ forcing. Aerosols and surface albedo change are estimated from historical scenarios of emissions and land use. Oscillatory and intermittent natural forcings (solar irradiance and volcanoes) are excluded. CFCs include not only chlorofluorocarbons, but all Montreal Protocol Trace Gases (MPTGs) and Other Trace Gases (OTGs). Uncertainty (for 5-95\% confidence) is $0.6 \mathrm{~W} / \mathrm{m}^{2}$ for total GHG forcing and $0.9 \mathrm{~W} / \mathrm{m}^{2}$ for aerosol forcing (Myhre et al 2013). After Hansen et al (2016).

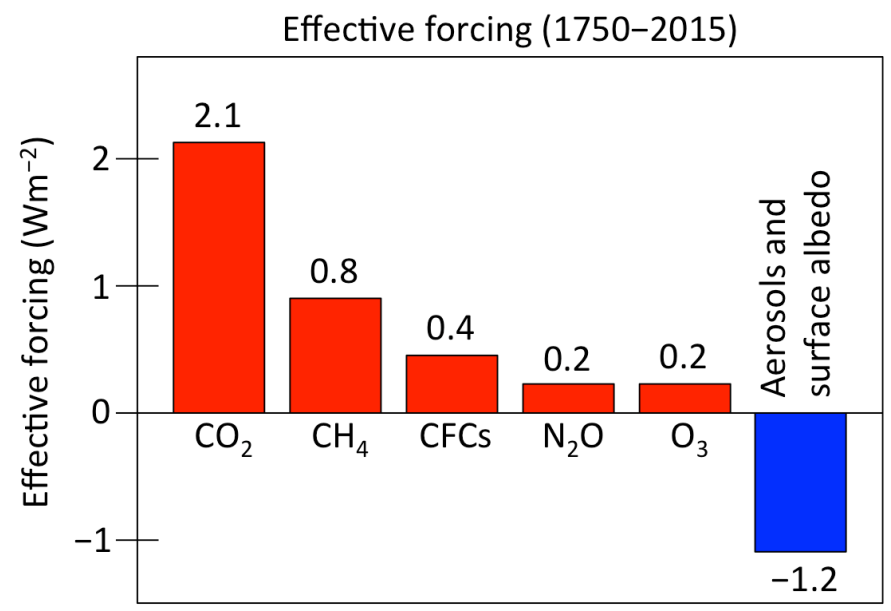


Figure 3. Assessment of $S^{a}$ in our main scenario. (a) Relative radiative contributions per process (medians shown only), and their total sum along with 95\% probability bounds. This follows the parameters outlined in Table 1 . The number of randomly perturbed (see Table 1 ) iterations is $\mathrm{N}=1000$. Note that $\Delta R_{\text {[WE] }}$ shows as a flat line at $0 \mathrm{Wm}^{-2}$ because it only becomes important at $t>$ $100,000 \mathrm{y}$. To avoid clutter, parameters are indicated in the legends with names of ' $X X$ ', in shorthand for ' $\triangle R_{[\mathrm{XXX}]}$ ' (b) Total temperature development through time, in relation to total radiative change given in (c), with $95 \%$ probability bounds. Blue bar indicates interval where "scaling/calibration" was determined (see text). (c) Calculated $S(t)$ with $95 \%$ probability bounds. For comparison, results are shown for two cases: one including carbon-cycle feedback $\left(\Delta R_{[\mathrm{CFB}]}\right)$ influences (blue); and one excluding these influences (red). Arrow demarcates where $S^{a}$ is measured, and the bracket show the interval where the $S^{\max }$ estimate is taken, as discussed in the text.

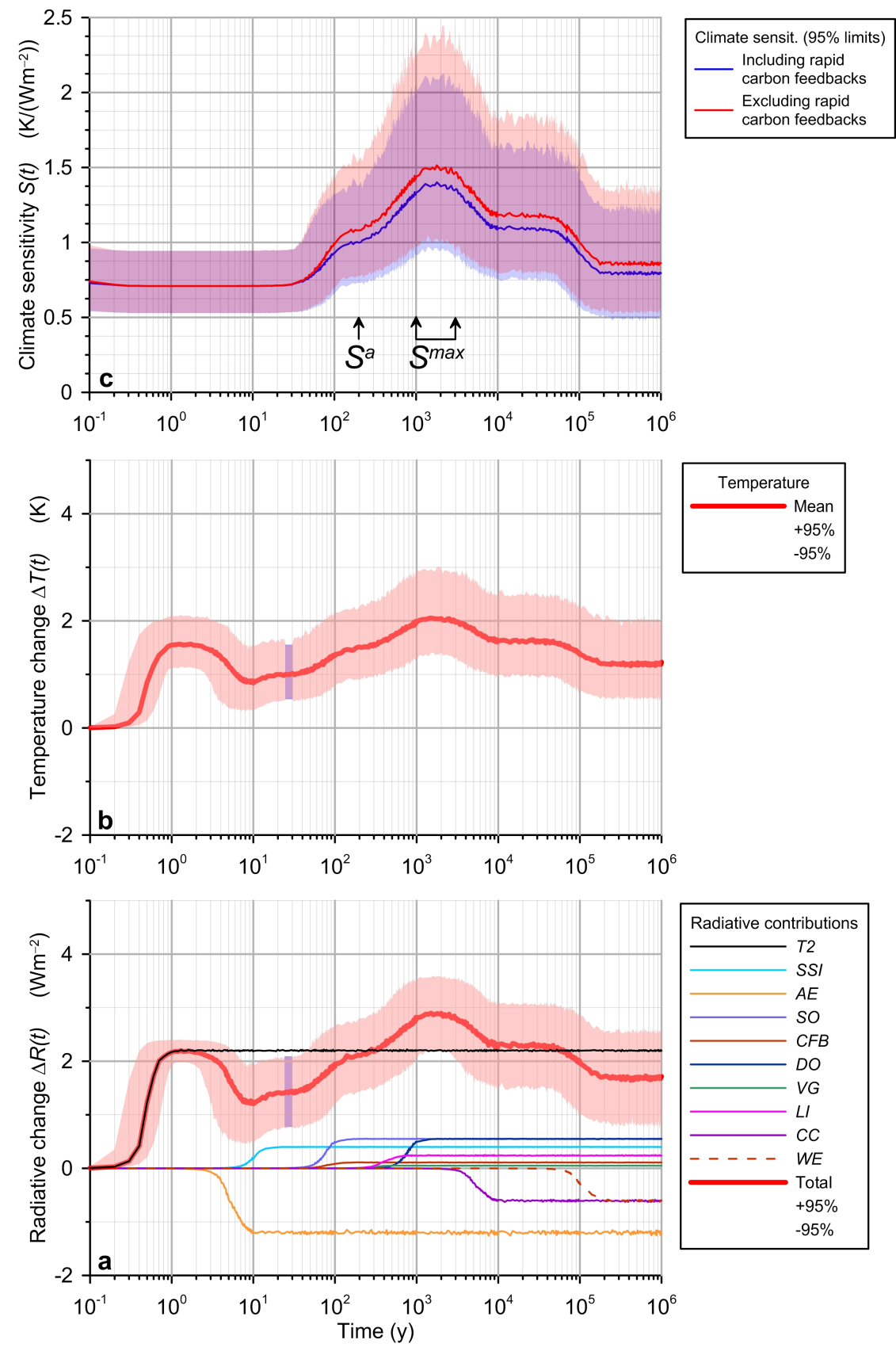


Figure 4. Histograms for "actuo-scenario." The various curves are determined at $t=200 \mathrm{y}$ for $S^{a}$ and as the average of $1000 \leq t \leq 3000 \mathrm{y}$ for $S^{\text {max }}$, as indicated in Figure $3 c$ and described in section 3.1.

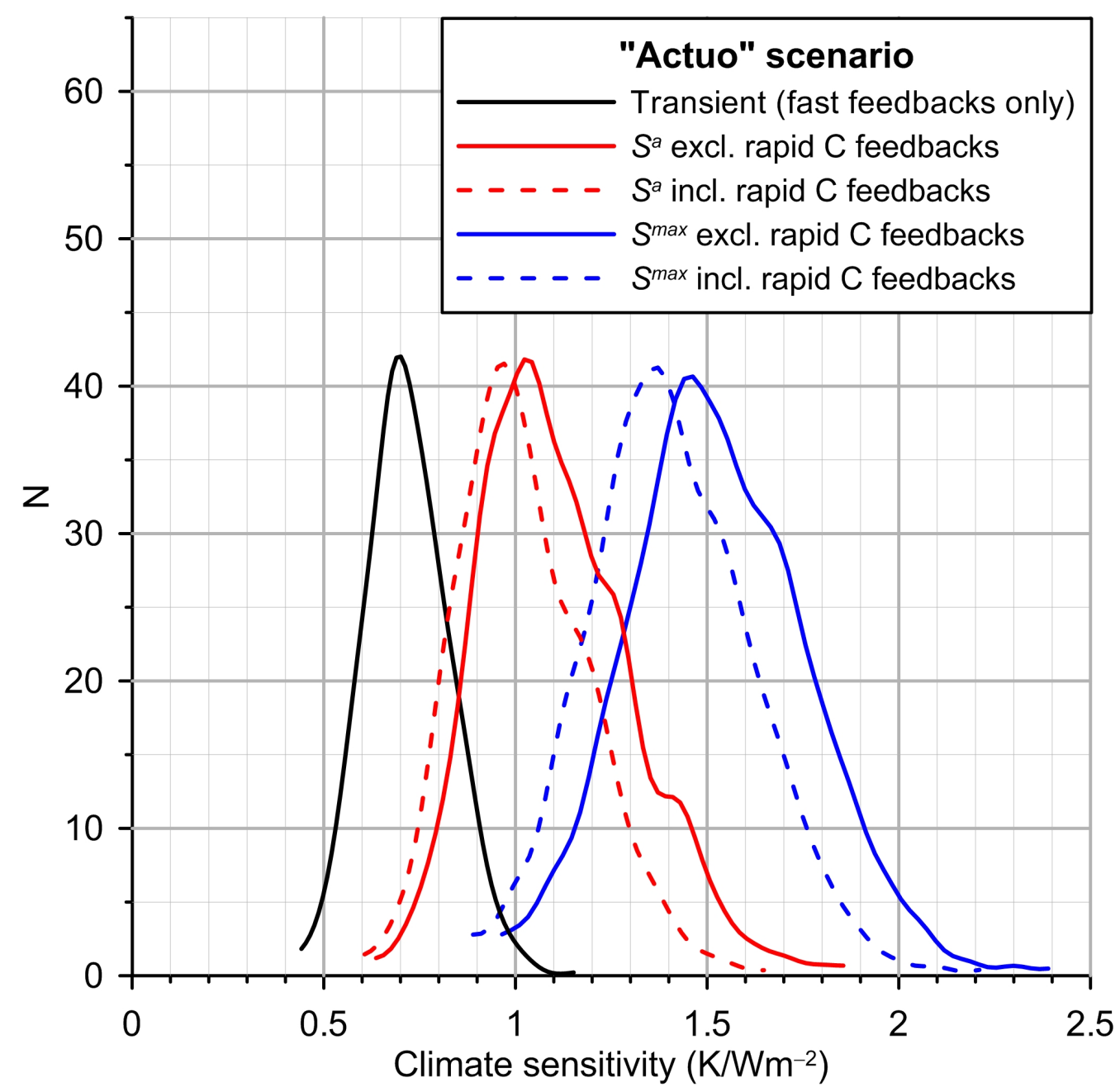


Figure 5. Assessment of $S_{[s f]}$ in our main palaeoscenario. (a) Relative radiative contributions per process (medians shown only), and their total sum along with $95 \%$ probability bounds. This follows the parameters outlined in Table 2. The number of randomly perturbed (see Table 2) iterations is $\mathrm{N}=1000$. To avoid clutter, parameters are indicated in the legends with names of ' $X X$ ', in shorthand for ' $\Delta R_{[\mathrm{Xx}]}$ '. (b) Total temperature development through time, in relation to total radiative change given in (c), with $95 \%$ probability bounds. Blue bar indicates interval where "scaling/calibration" was determined (see text). (c) Calculated palaeoclimate sensitivity with $95 \%$ probability bounds, for different definitions as discussed in the text.
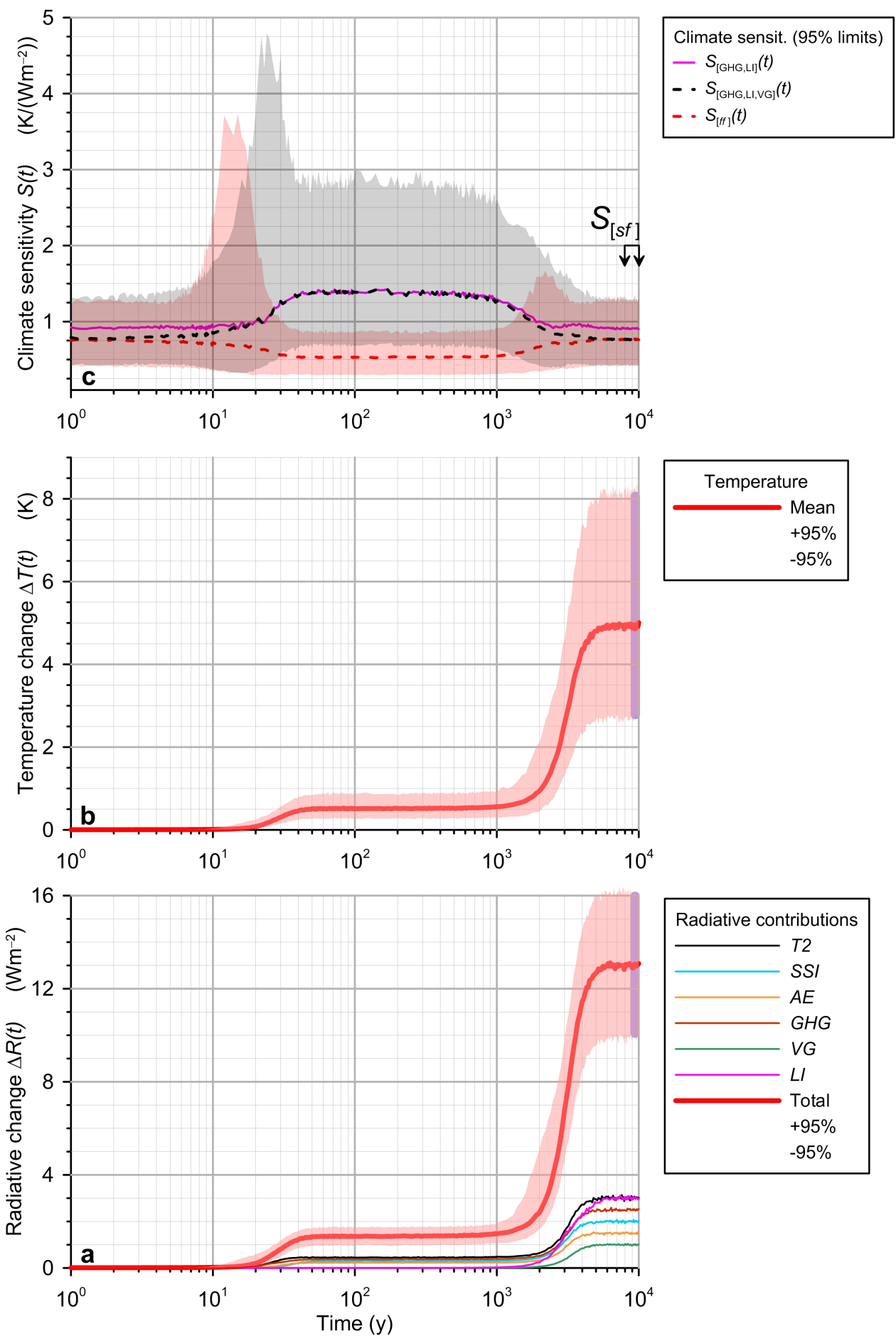
Figure 6. Histograms for the palaeo-scenario. The various curves are determined as the averages of $8000 \leq t \leq 10,000 \mathrm{y}$, as indicated in Figure $5 \mathrm{c}$ and described in section 3.2. The grey shading represents a scaled version of the distribution from PALAEOSENS (2012; their Figure 3c).

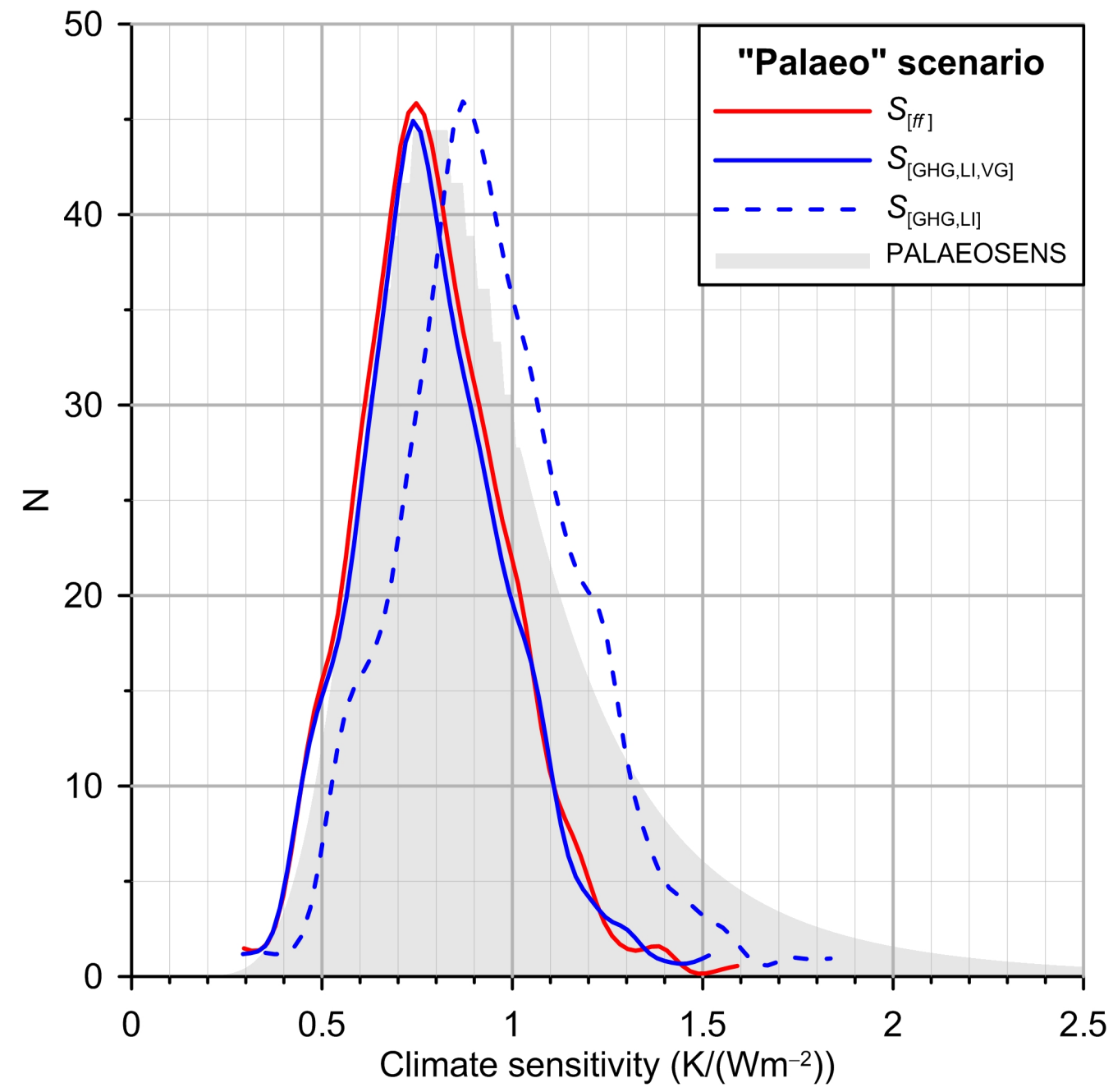


Figure 7. Analysing the classical $2 \mathrm{xCO}_{2}$ experiment in a feedback analysis framework. An initial perturbation in the radiative forcing $\Delta R_{F}$ leads without any further feedbacks to the Planck response (change in outgoing long-wave radiation, OLW), which are enhanced by further time-dependent feedback terms $\lambda_{i}(t)$.
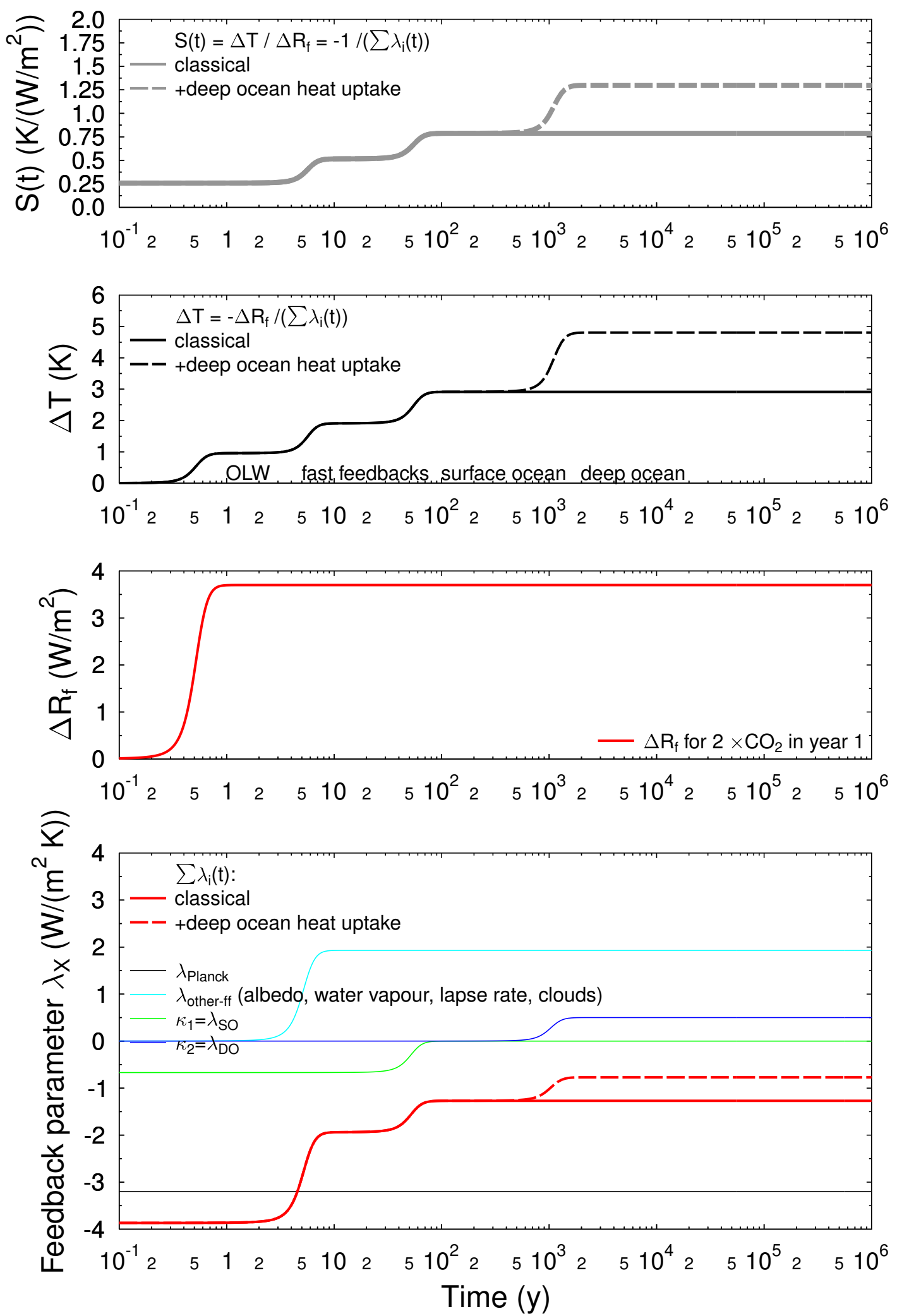